\title{
Solvent extraction of palladium(II) using diamides: A performing molecular system established through a detailed study of extraction kinetics.
}

\author{
Sayed-Ali Moussaoui, ${ }^{a}$ Anne Lélias, ${ }^{b}$ Bertrand Braibant, ${ }^{a}$ Daniel Meyer, ${ }^{a}$ Damien \\ Bourgeois $^{\mathrm{a}}$
}

a Institut de Chimie Séparative de Marcoule, ICSM, CEA, CNRS, ENSCM, Univ Montpellier, BP 17171, Marcoule, 30207 Bagnols-sur-Cèze, France.

b DMRC/SPTC/LCIS, CEA Marcoule, BP 17171, Marcoule, 30207 Bagnols-sur-Cèze, France.

damien.bourgeois@umontpellier.fr

\begin{abstract}
Palladium isolation and refining through solvent extraction suffer from limited stability of commercial reagents or limited availability of robust reagents in nitrate media. Several performing extraction solvents based on diamide reagents have been proposed, but their preparation requires synthetic chemistry skills. In the present work, we propose the use of readily accessible $N, N, N^{\prime}, N^{\prime}$-tetrahexylmalonamide (THMA). This reagent revealed superior distribution ratios and selectivity in comparison with previously used diamides for palladium(II) extraction from nitrate media in the frame of palladium recovery from waste. Furthermore, the benefit of excess dihexylamine (DHA) employed during the preparation of THMA was demonstrated through a gain in kinetics performance. Detailed analysis enabled to determine the best performing formulation of extraction solvent, which can be readily prepared from commercially available chemicals without any complex synthesis procedure nor purification step.
\end{abstract}

Keywords:

Solvent extraction; Kinetics; Palladium; Diamides; Synergy 


\section{Introduction}

Recycling of platinum Group Metals (PGM) has continuously been the object of extensive R\&D efforts due to their elevated cost and importance in many industrial sectors. ${ }^{1-3}$ The supply of PGM is limited by their very low natural abundance and the availability of natural ores in only a few countries (South Africa, Russia). ${ }^{4-6}$ The recent sanitary crisis has further revealed the weaknesses of the supply chain in most developed countries. Public policies push towards increasing the recovery of PGM from secondary resources to ensure the economy's resilience. ${ }^{7-10}$ Various complementary solutions have been proposed, based either on pyrometallurgical or hydrometallurgical processing. ${ }^{3,11,12}$ Nevertheless, whatever the technology employed, final isolation and purification of PGM rely generally on a solvent extraction stage. ${ }^{13,14}$ The existing industrial extracting molecules, mostly dialkyl sulfides and fatty amines, could not be successfully applied to hydrometallurgical processes dedicated to the recovery of PGM from waste as their selectivity scope or their stability is insufficient. ${ }^{15}$ As a consequence, several organic molecules have been developed after molecular design and synthesis route selection. ${ }^{16}$ The chemical synthesis of tailor-made molecules is not limited to solvent extraction: They can be employed in solvent impregnated ${ }^{17,18}$ or chelating resins, ${ }^{19}$ as ion exchange is also a technique of interest for the recovery of PGM in dilute solutions. Amide compounds play a central role, as the amide moiety is very stable in the highly acidic and oxidizing media employed. ${ }^{20}$ Monoamides are not efficient enough for PGM extraction. Thus, sulfide containing monoamides and various diamides, ${ }^{21,22}$ including aza- or thio-bearing diamides ${ }^{23,24}$ have been synthesized and successfully used in solvent extraction of PGM from chloride media. Malonamides proved to lead to very stable Pd(II) complexes, and to efficient extraction from nitrate media. ${ }^{15,25}$ Based on these results, we recently proposed a simple process to recover palladium from electronic waste using diamides previously developed in the frame of nuclear fuel reprocessing. ${ }^{20,26,27}$ The approach relies on the reformulation of the extraction solvent using existing available molecules. Although the approach seems promising, it relies on a molecule that has to be specifically prepared and which is only available in large quantities through custom synthesis companies, and not through the regular chemical suppliers. To the best of our knowledge, none of the above-presented new molecules has passed the proof of concept stage at the laboratory level due to the complexity of obtaining them on a large scale for further process development. Finally, it is essential to mention that in Europe, the marketing of a new molecule is hampered by REACH regulation, so that efficient solutions based on existing registered molecules are still needed. During our 
1 previous work, the fundamental studies performed along with the process development 2 studies revealed that the initial design of the chosen diamide, $N, N^{\prime}$-dimethyl- $N, N^{\prime}$ dibutylteradecylmalonamide (DBMA, Figure 1), was not optimized for selective Pd(II)

4 extraction. $^{26,28-30}$ DBMA was selected as this molecule is the former lanthanide/actinide separation molecule, so that it was readily available from French CEA. However, its molecular design has been performed targeting high distribution ratios for lanthanides(III) cations, ${ }^{31-33}$ and its ability to also extract palladium(II) was instead a side-effect. ${ }^{34,35}$ Thus, the possibility to envision a more simple diamide based solvent dedicated to selective palladium(II) extraction rapidly appeared, using $N, N, N^{\prime}, N^{\prime}$-tetrahexylmalonamide (THMA,

10 Figure 1), previously described for uranium(VI) extraction. ${ }^{36,37}$ Although the newly proposed diamide is not commercially available, it can be prepared in situ and employed without any purification in the extraction process. Thus, as starting reagents are available and easy to handle, it is possible to prepare the extraction solvent without specific operation in chemical synthesis. Furthermore, the study of the influence of the stoichiometry of reagents employed revealed that a slight excess of amine is beneficial to the performance of the extraction process. A detailed study of the thermodynamic and kinetic features enabled to evidence a synergy phenomenon between amine and diamide for $\operatorname{Pd}(\mathrm{II})$ extraction. Finally, the performance of the THMA could be extended to the extraction of Pt(IV) from chloride media.

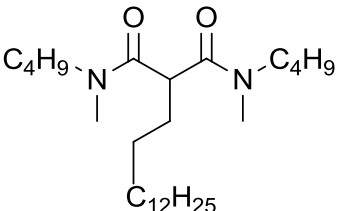

DBMA

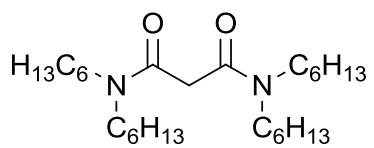

THMA

Figure 1: Chemical structures of diamides employed in the study

\section{Experimental}

\subsection{Chemical reagents}

$N, N^{\prime}$-dimethyl- $N, N$ '-dibutylteradecylmalonamide (98\% purity, DBMA, Figure 1) was kindly provided by the CEA, France. Production was performed by Pharmasynthèse (former Panchim), France, and the product was used without further purification. Palladium(II) nitrate hydrate $\left(\mathrm{Pd}\left(\mathrm{NO}_{3}\right)_{2} \cdot \mathrm{xH}_{2} \mathrm{O}\right.$, ca. $40 \% \mathrm{Pd}, 99.9 \%$ purity), palladium(II) chloride (99.9\% purity) and platinum(I $\square \mathrm{V}$ ) chloride (99.9\% purity) were purchased from Strem Chemicals. Iron(III) nitrate nonahydrate $\left(\mathrm{Fe}\left(\mathrm{NO}_{3}\right)_{3} \cdot 9 \mathrm{H}_{2} \mathrm{O}, \geq 98 \% \mathrm{Fe}\right)$, neodymium(III) nitrate hexahydrate 
$1 \quad\left(\mathrm{Nd}\left(\mathrm{NO}_{3}\right)_{3} \cdot 6 \mathrm{H}_{2} \mathrm{O}, 99.9 \%\right.$ purity), diethyl malonate (99\% purity) and dihexylamine (97\%

2 purity) were purchased from Sigma-Aldrich and used without further purification. Toluene,

3 Solvesso $^{\mathrm{TM}} 150$, diethyl ether, concentrated nitric acid $69.5 \%(\mathrm{w} / \mathrm{w})$, concentrated

4 hydrochloric acid $37 \%(\mathrm{w} / \mathrm{w})$ and anhydrous magnesium sulfate were purchased from Carlo

5 Erba reagents.

\subsection{Synthesis and characterization of $N, N, N^{\prime}, N^{\prime}$-tetrahexylmalonamide (THMA)}

A mixture of diethylmalonate $(8.09 \mathrm{~g}, 0.05 \mathrm{~mol})$ and dihexylamine $(20.1 \mathrm{~g}, 0.105 \mathrm{~mol}$,

2.1 equiv.) was heated under reflux (ca. $180^{\circ} \mathrm{C}$ ) for $7 \mathrm{~h}$. Every $30 \mathrm{~min}$, an argon flow was injected during $1 \mathrm{~min}$ to evacuate the produced ethanol through a distillation apparatus (see SI, Figure S1). The reaction mixture was then cooled to room temperature. The resulting product could be used directly in solvent extraction experiments. For characterization and detailed study, purification was performed as follows: The resulting mixture was dissolved in $100 \mathrm{~mL}$ diethyl ether and then washed with an aqueous $1 \mathrm{M} \mathrm{HCl}$ solution to remove unreacted dihexylamine $(4 \times 30 \mathrm{~mL})$, with an aqueous saturated solution of $\mathrm{NaHCO}_{3}(1 \times 30 \mathrm{~mL})$ and finally with brine $(1 \times 30 \mathrm{~mL})$. The recovered organic layer was dried over anhydrous $\mathrm{MgSO}_{4}$ and concentrated in vacuo. $N, N, N^{\prime}, N^{\prime}$-tetrahexylmalonamide (THMA, Figure 1) was obtained as a viscous pale yellow liquid (21.5 g, 98\% yield).

${ }^{1} \mathrm{H}$ NMR (400 MHz, $\left.\mathrm{CDCl}_{3}\right) \delta(p p m): 3.45\left(s, 2 \mathrm{H}, \mathrm{COCH}_{2} \mathrm{CO}\right) 3.34(d d, \mathrm{~J}=15.4,7.8 \mathrm{~Hz}, 4 \mathrm{H}$, $\left.\mathrm{N}-\mathrm{CH}_{2}\right), 3.32\left(\mathrm{dd}, \mathrm{J}=15.4,7.7 \mathrm{~Hz}, 4 \mathrm{H}, \mathrm{N}-\mathrm{CH}_{2}\right), 1.57-1.55\left(\mathrm{~m}, 8 \mathrm{H}, \mathrm{N}-\mathrm{CH}_{2}-\mathrm{CH}_{2}\right), 1.32-1.29$ $\left(m, 24 \mathrm{H}, \mathrm{CH}_{2}\right) 0.92\left(t, \mathrm{~J}=6.7 \mathrm{~Hz}, 6 \mathrm{H}, \mathrm{CH}_{3}\right), 0.88(t, \mathrm{~J}=6.6 \mathrm{~Hz}, 6 \mathrm{H}, \mathrm{CH},) ;{ }^{13} \mathrm{C} \mathrm{NMR}(100.6$ $\left.\mathrm{MHz}, \mathrm{CDCl}_{3}\right) \delta(\mathrm{ppm}):$ 166.6, 48.4, 46.0, 40.8, 31.5, 31.5, 28.9, 27.5, 26.6, 26.5, 22.5, 13.9, 13.9, IR (neat) $v\left(\mathrm{~cm}^{-1}\right): 2927,2903,2850,1634(C=O), 1456,1420,1376$.

\subsection{Solvent extraction}

Aqueous phases containing the desired metallic cations were prepared from the corresponding metallic salts $\left(\mathrm{Pd}\left(\mathrm{NO}_{3}\right)_{2} \cdot \mathrm{xH}_{2} \mathrm{O}, \mathrm{PdCl}_{2} \cdot 2 \mathrm{H}_{2} \mathrm{O}, \mathrm{Fe}\left(\mathrm{NO}_{3}\right)_{3} \cdot 9 \mathrm{H}_{2} \mathrm{O}, \mathrm{Nd}\left(\mathrm{NO}_{3}\right)_{3} \cdot 6 \mathrm{H}_{2} \mathrm{O}\right.$, $\mathrm{PtCl}_{4}$ ) dissolved in an aqueous $\mathrm{HNO}_{3}$ or $\mathrm{HCl}$ solution of desired concentration as described in the text. Organic phases were prepared by diluting THMA, DMBA and/or DHA in the appropriate diluent (toluene, Solvesso ${ }^{\mathrm{TM}} 150$ ) to reach the concentrations given in the text. 
1 The organic phases were pre-equilibrated by bringing them into contact for 30 min with a

2 five-fold volume of an aqueous solution of $\mathrm{HNO}_{3}$ or $\mathrm{HCl}$ of molarity identical to that of the aqueous metal solution employed for the extraction step.

Extraction experiments were carried out in $2 \mathrm{~mL}$ Eppendorf tubes with equal volumes of the aqueous and organic phases $(\mathrm{A} / \mathrm{O}=1)$. The two phases were shaken with a thermostated orbital mixer (Eppendorf Thermomixer ${ }^{\circledR} \mathrm{C}$ ) for $1 \mathrm{~h}$ to $24 \mathrm{~h}$ at $20^{\circ} \mathrm{C} \pm 2^{\circ} \mathrm{C}$. Unless otherwise stated in the text, the stirring speed was set at $2000 \mathrm{rpm}$. Tubes were then centrifuged to ensure good phase separation.

For each extraction performed, aliquots of the aqueous phases $(100 \mu \mathrm{L})$, before and after extraction, were directly diluted with a $2 \% \mathrm{HNO}_{3} / \mathrm{HCl}$ aqueous solution (90/10). After extraction, aliquots of the loaded organic phases $(500 \mu \mathrm{L})$ were back-extracted during $1 \mathrm{~h}$ with $1 \mathrm{~mL}$ of a $0.1 \mathrm{M}$ aqueous thiourea solution. Resulting phases were separated and $250 \mu \mathrm{L}$ of the final aqueous phase were taken and diluted with a $2 \% \mathrm{HNO}_{3} / \mathrm{HCl}$ aqueous solution $(90 / 10)$. Evidence from preliminary investigations showed that all extracted metals were totally stripped from loaded organic phases during the process, and that no metal precipitation occurred prior to analysis. Dilution factors have been chosen so that a minimum 10-fold dilution is operated to avoid matrix effects during analysis.

\subsection{Analytical determination of metal content}

Metals concentration in each solution was determined using inductively coupled plasma atomic emission spectroscopy (ICP/AES, SPECTRO ARCOS ICP Spectrometer, AMETEK Materials Analysis). The selected spectral lines to assay metals were free from interference. The given concentrations were calculated as the average of three replicates at different wavelengths for each metal. Relative standard deviations have been determined and lie between 1 and 3\%. Quantification limits (LoQ) in each analyzed phase were determined for each metal from the dilution factor applied and the background equivalent concentration calculated by the spectrometer for each optical line. Confidence intervals were selected taking into account the error of the spectrometer and the precision of the equipment used for dilution. Altogether, the relative errors were found to be between 5\% and 10\%. All results showed a 


\subsection{Expression of results}

Assuming that the volume change of both phases is neglected during extraction, the metal distribution ratio $(D)$ and the metal extraction percentage $(\% E)$ were determined using equations (1) and (2) below:

$$
D=\frac{[M]_{\text {org }}}{[M]_{a q}}
$$

$$
\% E=\left(\frac{V_{\text {org }}[M]_{\text {org }}}{V_{a q}[M]_{a q, i}}\right) \times 100
$$

Where $[M]_{a q, i},[M]_{a q}$ and $[M]_{\text {org }}$ denote, respectively, the metal concentration in the initial aqueous phase, the metal concentration in the aqueous phase and the organic phase after extraction, and $\mathrm{V}_{\mathrm{aq}}$ and $\mathrm{V}_{\text {org }}$ denote, respectively, the volumes of aqueous and organic phases.

The separation factors were calculated using the following equation (3):

$$
S_{M_{1} / M_{2}}=\frac{D_{M_{1}}}{D_{M_{2}}}
$$

Where $D_{M_{1}}$ and $D_{M_{2}}$ denote the distribution ratios of the metal $M_{1}$ and the metal $M_{2}$ respectively.

\subsection{Interfacial tension measurements}

All interfacial tension measurements were carried out using a Krüss spinning drop tensiometer (SDT) equipped with a high resolution USB3 camera. The tensiometer is combined with the ADVANCE software. This software performs image analysis applying either the approximation functions of Vonnegut, or making use of an evaluation algorithm based on a Young-Laplace fit. For the current measurements, Young-Laplace-fit equation was used for interfacial tension determination. The densities of all samples were determined using DSA 5000 densimeter at $23^{\circ} \mathrm{C}$. All the organic phases were pre-equilibrated by contacting them for $30 \mathrm{~min}$ with a five-fold volume of $3 \mathrm{M}$ aqueous nitric acid concentration. The capillary was filled with the heavy phase $\left(3 \mathrm{M} \mathrm{HNO}_{3}\right)$. A drop of the sample (organic phase) was injected with a syringe against the inner wall of the horizontally held capillary, so that the drop remained stuck approximately in the center of the capillary. The capillary was then placed on the filled closure cap so that it was sealed. Calibration of the tensiometer were 
performed before each measurement to obtain the image scale. Interfacial tension measurements were performed at a controlled temperature of $23^{\circ} \mathrm{C}$ at a high rotation rate (>5000 rpm). The reported values were recorded after the drops reached equilibrium, and no further decrease in interfacial tension values was observed.

\section{Results and discussion}

\subsection{Extraction of Pd with THMA and DBMA}

In addition to their capacity to remove minor actinides, diamides have shown an affinity to extract $\mathrm{Pd}(\mathrm{II})$ from nitric acid media. Accordingly, the selective extraction of $\mathrm{Pd}(\mathrm{II})$ from nitrate media was reported with DBMA. DBMA remains complicated to prepare (three synthesis steps, and purification on silica gel column), making a competitive process dependent on excellent recycling of extraction solvent. Furthermore, for efficient extraction of $\mathrm{Pd}(\mathrm{II})$, it was necessary to increase the concentration of the extractant to $0.6 \mathrm{~mol} / \mathrm{L}$, i.e. about $300 \mathrm{~g} / \mathrm{L}$, which makes the initial investment in extraction solvent substantial. On the contrary, THMA is a $N, N, N^{\prime}, N^{\prime}$-tetrasubstituted malonamide that is much simpler to prepare. Furthermore, it revealed to be an excellent candidate for the selective extraction of Pd(II): The Pd(II) extraction performances of THMA have been assessed in comparison with DBMA, in conditions where DBMA presents good Pd(II) distribution ratios and good selectivity regarding $\mathrm{Fe}(\mathrm{III})$ and $\mathrm{Nd}(\mathrm{III})$ (Table 1). THMA exhibited overall much better extraction of Pd(II) than DBMA across the whole range of extractant concentrations. Palladium distribution ratios $D_{\mathrm{Pd}}$ with THMA were between 10 and 100 times higher than that with DBMA, and still using only 0.3M THMA, the concentration of residual $\operatorname{Pd}(\mathrm{II})$ in the final aqueous layer was below the detection limit of the ICP-OES analysis $\left(D_{\mathrm{Pd}}>70\right)$. The quantitative extraction of Pd(II) with THMA can induce a significant reduction in extractant charge in the organic phase since both diamides are structural isomers, having the same number of carbon atoms (27), and thus the same molecular weight $\left(438.7 \mathrm{~g} \cdot \mathrm{mol}^{-1}\right)$.

It was previously reported that the selective extraction of $\mathrm{Pd}(\mathrm{II})$ over $\mathrm{Nd}(\mathrm{III})$ and Fe(III) with DBMA was strongly dependent on two key parameters: The concentration of DBMA for $\mathrm{Nd}(\mathrm{III})$ and the aqueous nitric acid concentration for $\mathrm{Fe}(\mathrm{III}) .{ }^{26}$ Therefore, the 30 optimized conditions to reach selective Pd(II) extraction with DBMA have been established at $310,5-0,6 \mathrm{M}$ DBMA in toluene with a $3 \mathrm{M}$ aqueous $\mathrm{HNO}_{3}$ solution. THMA showed an impressively high selective extraction of palladium in the presence of $\mathrm{Fe}(\mathrm{III})$ and $\mathrm{Nd}(\mathrm{III})$ 
1 compared to DBMA. For instance, at 0.3M THMA, $S_{\mathrm{Pd} / \mathrm{Fe}}$ and $S_{\mathrm{Pd} / \mathrm{Nd}}$ were above 11600 and 235000 respectively, and $\operatorname{Pd}(\mathrm{II})$ extraction was quantitative. Experimentally, after extraction 3 Pd(II) could not be detected in the aqueous layer $\left(D_{\mathrm{Pd}}>70\right)$, and $\mathrm{Nd}(\mathrm{III})$ could not be detected 4 in the organic layer $\left(D_{\mathrm{Nd}}<0.002\right)$. Fe(III) was barely quantified in the organic layer $\left(D_{\mathrm{Fe}}=\right.$ 5 0.006). In comparison, for the same concentration for DBMA, $S_{\mathrm{Pd} / \mathrm{Fe}}$ and $\mathrm{S}_{\mathrm{Pd} / \mathrm{Nd}}$ were 180 and 650 , respectively, with $\mathrm{Pd}(\mathrm{II})$ distribution ratio of 4 only. The increase in extractant 7 concentrations leads to a decrease in the selectivity regarding $\mathrm{Fe}(\mathrm{III})$ or $\mathrm{Nd}(\mathrm{III})$ with DBMA 8 as previously reported. When using THMA, the distribution ratios of both $\mathrm{Fe}(\mathrm{III})$ and $\mathrm{Nd}(\mathrm{III})$ 9 also increased with concentration, but remained very low (below 0.1 ) so that $S_{\mathrm{Pd} / \mathrm{Fe}}$ and $S_{\mathrm{Pd} / \mathrm{Nd}}$ were still much higher than those obtained using the same DBMA concentration (Table 1).

Table 1. Distribution ratios of $\mathrm{Pd}(\mathrm{II}), \mathrm{Fe}(\mathrm{III})$ and $\mathrm{Nd}(\mathrm{III})$ and $\mathrm{Pd} / \mathrm{Fe}, \mathrm{Pd} / \mathrm{Nd}$ selectivity $S_{\mathrm{Pd} / \mathrm{Fe}}, S_{\mathrm{Pd} / \mathrm{Nd}}$ after extraction using THMA and DBMA in toluene, from an aqueous $3 \mathrm{M}$ $\mathrm{HNO}_{3}$ phase. Initial $[\mathrm{Pd}]_{\mathrm{aq}} 500 \mathrm{mg} / \mathrm{L}, 1 \mathrm{~h}$ extraction, stirring speed $2000 \mathrm{rpm}$.

\begin{tabular}{ccccccc}
\hline & THMA & DBMA & THMA & DBMA & THMA & DBMA \\
& $0.3 \mathrm{M}$ & $0.3 \mathrm{M}$ & $0.5 \mathrm{M}$ & $0.5 \mathrm{M}$ & $0.6 \mathrm{M}$ & $0.6 \mathrm{M}$ \\
\hline$D_{\mathrm{Pd}}$ & $>70^{*}$ & 4.0 & $>70^{*}$ & 10 & $>70^{*}$ & 15 \\
$D_{\mathrm{Fe}}$ & 0.006 & 0.02 & 0.05 & 0.2 & 0.09 & 0.31 \\
$D_{\mathrm{Nd}}$ & $<0.002^{*}$ & 0.08 & 0.038 & 0.37 & 0.069 & 0.83 \\
\hline$S_{\mathrm{Pd} / \mathrm{Fe}}$ & $>11600$ & 200 & $>1400$ & 50 & $>778$ & 48 \\
$S_{\mathrm{Pd} / \mathrm{Nd}}$ & $>35000$ & 50 & $>1840$ & 27 & $>1014$ & 18 \\
\hline
\end{tabular}

11 Note: * When concentration in the final aqueous phase is below the detection limit, only a lower $D$ value can be 12 determined. Similarly, when concentration in the final organic phase is below the detection limit, only a higher $D$ 13 value can be determined.

Altogether, this analysis rapidly emphasized the very interesting features of THMA over DBMA in the selective extraction of Pd(II). Regarding the Pd(II) selective isolation process we recently proposed, using THMA instead of DBMA should lead to a more efficient process, based on lower stage numbers in extraction and scrubbing sequences, and using a lower amount of extracting molecule. However, we were surprised to notice a sudden drop in performance when lowering the THMA concentration to $0.2 \mathrm{M}$ or below. Particularly low

20 Pd(II) distribution ratios were sometimes obtained, depending on the batches of THMA used.

21 Careful examination of the NMR spectra of the corresponding batches was conducted and revealed residual traces of dihexylamine (DHA) in the solvent. Also, equilibrium was not reached after $1 \mathrm{~h}$ extraction: The extraction with THMA is incomplete after $1 \mathrm{~h}$ shaking (see SI, Figure S2), whereas with DBMA we found during our previous studies that extraction equilibrium was reached after 10 min only, working in toluene and using the same aqueous 
1 layer $\left(\left[\mathrm{HNO}_{3}\right]=3 \mathrm{M}\right)$. This drawback led us to investigate in detail the impact of THMA

2 purity on extraction performances, and especially on the kinetics of $\mathrm{Pd}(\mathrm{II})$ extraction.

\subsection{Impact of added DHA on Pd(II) extraction with THMA}

Synthesis of THMA involves DHA as a starting material. High molecular weight amines and quaternary ammonium salts have been used among nitrogen-containing extractants for the extraction of PGM from chloride media. ${ }^{38-46}$ In addition to their extraction properties, their role as a catalyst in the extraction of $\mathrm{Pd}(\mathrm{II})$ from aqueous hydrochloric acid solutions has been documented in previous studies. ${ }^{47-50}$ Incorporation of an amine moiety into an amide based extractant proved superior performances for $\mathrm{Pd}(\mathrm{II})$ from nitrate media. However, Pd(II) extraction with amine-based functions from nitrate media has been rarely reported in the literature. ${ }^{51-53}$ Thus, the impact of controlled addition of DHA to pure THMA on the extraction of $\mathrm{Pd}(\mathrm{II})$ from nitric acid media was investigated. Firstly, a well-purified batch of THMA was prepared and fully characterized (see SI, Figures S3 and S4, and Table S1). Working with this batch confirmed i) the excellent performance regarding $\operatorname{Pd}(\mathrm{II})$ extraction, and ii) the slower kinetics of $\mathrm{Pd}(\mathrm{II})$ extraction at low THMA concentrations, compared to previous results with DBMA. Then, the concentration of THMA was set at $0.2 \mathrm{M}$, and DHA was added in quantity varying from 0 to $100 \mathrm{~mol} \%$ respective to THMA. For a contact period of $24 \mathrm{~h}$, excellent $\mathrm{Pd}(\mathrm{II})$ distribution ratios could be obtained even at this relatively low THMA concentration ( $D_{\mathrm{Pd}}=28$ with $0.2 \mathrm{M}$ THMA in toluene after $24 \mathrm{~h}$ ). DHA addition only had marginal effect, since the $D$ could reach only 32-35 (see Figure 3). Finally, using only DHA $0.2 \mathrm{M}$ in toluene, very low palladium distribution ratio was found $\left(D_{\mathrm{Pd}}=0.1\right.$ at equilibrium, after $24 \mathrm{~h}$ ) which confirms that secondary amines are not good $\mathrm{Pd}(\mathrm{II})$ extracting molecules from nitrate media.

In order to investigate in detail the kinetics effects, extraction conditions were modified in order to disfavor mass transfer through lowering of the interfacial area between aqueous and organic phases. Although it is difficult to determine with precision the interfacial area, it is clear that it depends on the shearing rate, thus on stirring rate. A visual study of the impact of the stirring rate on the mixing of both phases revealed that dispersion of organic phase into aqueous phase occurs at stirring rate between 800 and $1000 \mathrm{rpm}$ (see SI, Figure S5). At higher speed, emulsification of the biphasic system is well visible, and it can be assumed that the concentration in metal is homogeneous in each phase. Mass transfer is, nevertheless, probably still limited by the reduced interfacial area, and thermodynamic equilibrium is reached after longer shaking time. This was well evidenced through the study 
1 of Pd(II) extraction yield after 1 min (see SI, Figure S5). Therefore, the stirring speed was set 2 at $1200 \mathrm{rpm}$.

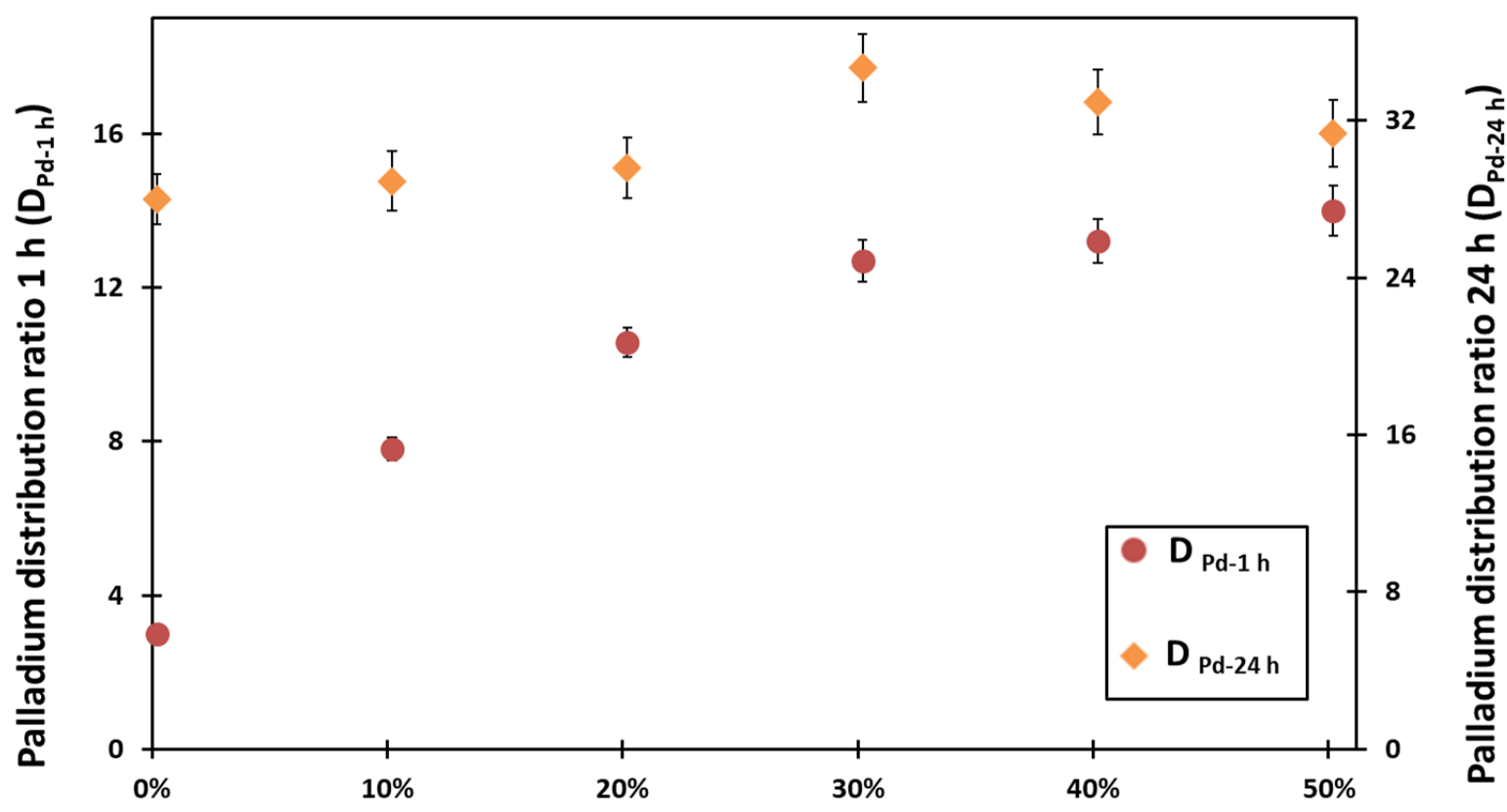

In these conditions, the palladium distribution ratio $\left(D_{\mathrm{Pd}}\right)$ drops to 3 ( $75 \%$ extraction percentage) using pure THMA $0.2 \mathrm{M}$ in toluene after $1 \mathrm{~h}$. When DHA was added to $0.2 \mathrm{M}$ THMA in toluene, the $\mathrm{Pd}(\mathrm{II})$ distribution ratio determined after $1 \mathrm{~h}$ extraction increased significantly (Figure 3). It reached a maximum at 14 (93\% extraction yield) when $50 \mathrm{~mol} \%$ DHA were added to THMA (thus, the extraction solvent is a 0.2M THMA / 0.1M DHA solution). The increase in the palladium distribution ratio was somehow still limited, and remained below the distribution ratio obtained in the same conditions after $24 \mathrm{~h}$ (Figure 3 ). Then, above 50 mol\% of added DHA, there is no more benefit of DHA addition. Moreover, a further increase in the molar percentage of added DHA led to a decrease in the extraction efficiency of Pd(II) (see SI, Figure S6). For instance, when using THMA with 90 mol\% added DHA, $D_{\text {Pd }}$ dropped to 2 (69\% extraction yield).

The marked increase of $\mathrm{Pd}(\mathrm{II})$ extraction at short durations could not be related to a change in interfacial surface, as no effect of DHA on interfacial tension was observed (see SI, 
1 Figure S7). Neither did viscosity change significantly up to $50 \mathrm{~mol} \%$ added DHA. We 2 therefore assume that the addition of DHA does not induce any extra interfacial activity, and that the observed results may instead be linked to chemical limits of the extraction kinetics. An increase in viscosity of the extraction solvent was noticed when the added DHA quantity exceeded $80 \mathrm{~mol} \%$. This increase in viscosity can be invoked here to explain the lower extraction yield at short durations as the increase in viscosity leads to reduced diffusion of molecules and ions. High molecular weight amines have been reported to extract nitric acid, ${ }^{54}$ and the increase in viscosity probably originates in the aggregation of DHA-nitrate species formed upon extraction of nitric acid by DHA. ${ }^{55,56}$ Visually, mixing of both phases was still efficient. A dedicated experimental set-up with a controlled interfacial area would be required to investigate in detail the effect of added DHA on the Pd(II) transfer kinetics. However, the experimental approach we propose is simple for preliminary investigations and we limited the following studies to $50 \mathrm{~mol} \%$ added DHA.

\subsection{Pd extraction kinetics with mixed THMA/DHA systems}

In order to precise the effect of DHA on the extraction kinetics, experiments were performed at short extraction durations (1 to $6 \mathrm{~min}$ ). The concentration of THMA in toluene was still set at $0.2 \mathrm{M}$, and controlled amount of DHA was added (10 mol\% to $50 \mathrm{~mol} \%)$. For each point in each series, a separate experiment was carried out, and the reported extraction time corresponds to the shaking time. The average absolute error in extraction time for each point was determined as the delay between the agitation turnoff and the time required to reach the maximum centrifugation speed. Assuming that afterwards during centrifugation mass transport is negligible, the time absolute errors are estimated at 6 seconds for each point, and are positive. A first-order model was used to interpret the experimental data. The rate of palladium extraction can be expressed as follows:

$$
-\frac{d[P d]_{a q}}{d t}=k\left([P d]_{a q, t}-[P d]_{a q, e q}\right)
$$

The integration of equation (4) gives equation (5):

$$
\ln \left([P d]_{a q, t}-[P d]_{a q, e q}\right)=-k t+\ln \left([P d]_{a q, 0}-[P d]_{a q, e q}\right)
$$


Where $k$ is the rate constant, $t$ is the time, $[P d]_{a q, t}$ is the concentration of $\mathrm{Pd}$ in the 2 aqueous phase at time $t,[P d]_{a q, e q}$ is the concentration of $\mathrm{Pd}$ in the aqueous phase at 3 equilibrium (see SI, Table S2) and $[P d]_{a q, 0}$ is the initial concentration of $\mathrm{Pd}$ in the aqueous 4 phase. In Figure 4, the plots of $\ln \left([P d]_{a q, t}-[P d]_{a q, e q}\right)=f(t)$ are represented for four chosen samples: (a) Pure THMA, (b) THMA + 10 mol\% DHA, (c) THMA + 20 mol\% DHA and (d) THMA + 50 mol\% DHA. The data of each sample is in agreement with the first order model as they can be modelled by a straight line.



Figure 4. First order model for the extraction of $\mathrm{Pd}(\mathrm{II})$ with pure THMA and mixed THMA/DHA systems in toluene. THMA concentration $0.2 \mathrm{M}$, and $10 \mathrm{~mol} \%$ DHA, $20 \mathrm{~mol} \%$ DHA and $50 \mathrm{~mol} \%$ DHA, initial $[\mathrm{Pd}]_{\mathrm{aq}} 500 \mathrm{mg} / \mathrm{L},\left[\mathrm{HNO}_{3}\right]_{\mathrm{aq}} 3 \mathrm{M}$, stirring speed $1200 \mathrm{rpm}$.

The extraction kinetics of $\mathrm{Pd}(\mathrm{II})$ is enhanced in the presence of DHA, with a regular increase in the observed rate constants (Figure 4). The rate constant increased from 0.028 $\min ^{-1}$ for the extraction with pure THMA to $0.116 \mathrm{~min}^{-1}$ with $50 \mathrm{~mol} \%$ added DHA, corresponding to an extraction half-time of $25 \mathrm{~min}$ and $6 \mathrm{~min}$ respectively. Thus, without DHA, Pd(II) extraction is slow, but occurs. The addition of 10 mol\% DHA leads to doubling of the rate constant (half-time divided by almost 2). The increase is then proportional to the quantity of added DHA (see SI, Figure S8). Interestingly, the observed rate constant $\left(\mathrm{k}_{\mathrm{obs}}\right)$ can 
1 be decomposed into two contributions, $\mathrm{k}_{\text {THMA }}$ (obtained when no DHA is added,

$2 \mathrm{k}_{\mathrm{THMA}}=0.028 \mathrm{~min}^{-1}$ ) and $\mathrm{k}_{\mathrm{DHA}}$ (equation (6)).

$$
k_{o b s}=k_{T H M A}+k_{D H A}
$$

3

4 5

The contribution $\mathrm{k}_{\mathrm{DHA}}$ is then proportional to the DHA quantity (see SI, Figure S8), as given by equation (7), where [DHA] is the concentration in DHA in mol. $\mathrm{L}^{-1}$ :

$$
k_{D H A}=0.87[D H A]
$$

As thermodynamic outcome of the $\operatorname{Pd}(\mathrm{II})$ extraction is almost the same in each case (Figure 3), this result demonstrates that DHA has principally a kinetic effect. Analysis of the observed rate constant suggests that two mechanisms occur simultaneously, i) a direct extraction with THMA, and ii) an indirect one mediated by DHA, and of first order respective to DHA. As stated above, a more detailed study employing adequate experimental tools would be necessary to reach a complete mechanistic understanding. These results are, nevertheless, sufficient to justify i) that slow kinetics are only observed at low THMA concentration, and ii) that DHA is involved in the formation of intermediate molecular species responsible for $\mathrm{Pd}(\mathrm{II})$ extraction.

The effect of the aqueous nitric acid concentration was studied, and results showed that the kinetics enhancement is strongly dependent on the aqueous nitric acid concentration: When using a $5 \mathrm{M}$ aqueous $\mathrm{HNO}_{3}$ solution, no more effect of added DHA was observed (Figure 5). Palladium distribution ratio obtained after $1 \mathrm{~h}$ extraction remained constant ( 2) for the entire range of added DHA. After $24 \mathrm{~h}$ of extraction, palladium distribution were found to lie around 10 (see SI, Figures S9 and S10). The lack of kinetic effect when using a higher concentration of aqueous $\mathrm{HNO}_{3}$ is possibly due to the fact that under these conditions, in the organic phase, DHA $\left(\mathrm{pK}_{\mathrm{a}}=11.0\right.$ in ethanol-water mixture) is fully protonated by $\mathrm{HNO}_{3}$. Thus, using a $5 \mathrm{M}$ aqueous $\mathrm{HNO}_{3}$ solution, only the extraction promoted by THMA may be observed. 


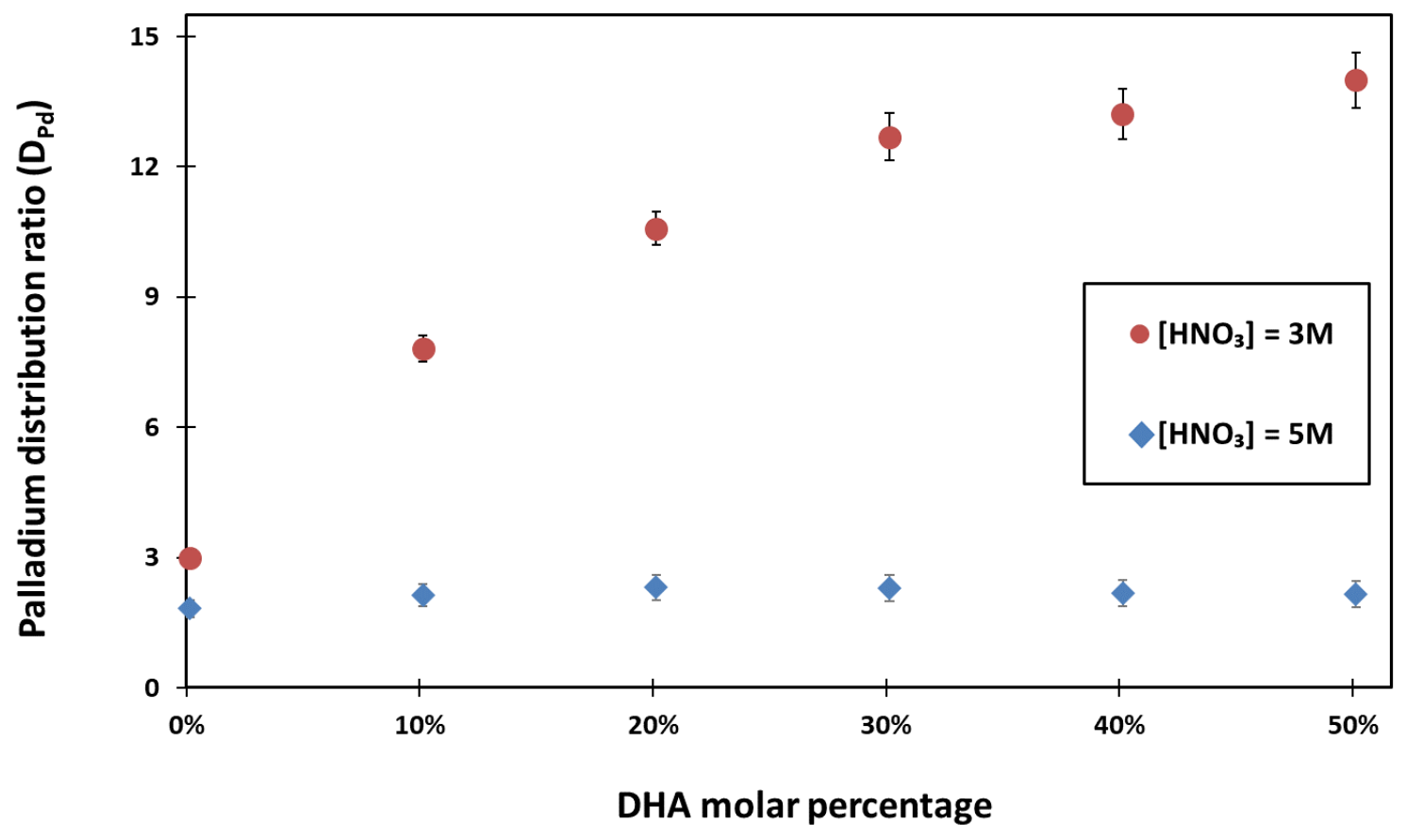

2 Figure 5. Variation of the $\mathrm{Pd}(\mathrm{II})$ distribution ratio with the aqueous nitric acid concentration 3 with mixed THMA/DHA systems in toluene, 0.2M THMA concentration, DHA molar 4 percentage $0 \%$ to $50 \%$, initial $[\mathrm{Pd}]_{\mathrm{aq}} 500 \mathrm{mg} / \mathrm{L}, 1 \mathrm{~h}$ extraction, stirring speed $1200 \mathrm{rpm}$.

\subsection{Extraction solvent formulation: optimization of added DHA quantity}

These results suggest that addition of $50 \mathrm{~mol} \%$ DHA is the optimum for improvement of extraction kinetics. However, when the THMA quantity is fixed, the addition of extra DHA leads to a higher total amount of extractant employed. Thus, it could be argued that better performance results also from the use of a higher amount of extractant. We therefore examined the impact of controlled DHA addition to THMA when total concentration in extracting molecules is fixed, ie. when $[$ THMA $]+[\mathrm{DHA}]=0.2 \mathrm{M}$. Thus, the addition of DHA is here accompanied by a lowering of the THMA concentration. The total mass of used

14 extractant also decreases, as the DHA is lighter than the THMA. As it is preferable to present 15 results using molar quantities than weight, we did not perform the study using a constant 16 weight in extractant. The $\mathrm{Pd}(\mathrm{II})$ distribution ratios obtained were plotted against the molar ratio of DHA $\left(\mathrm{x}_{D H A}\right)$ in the extraction solvent (Figure 6): 


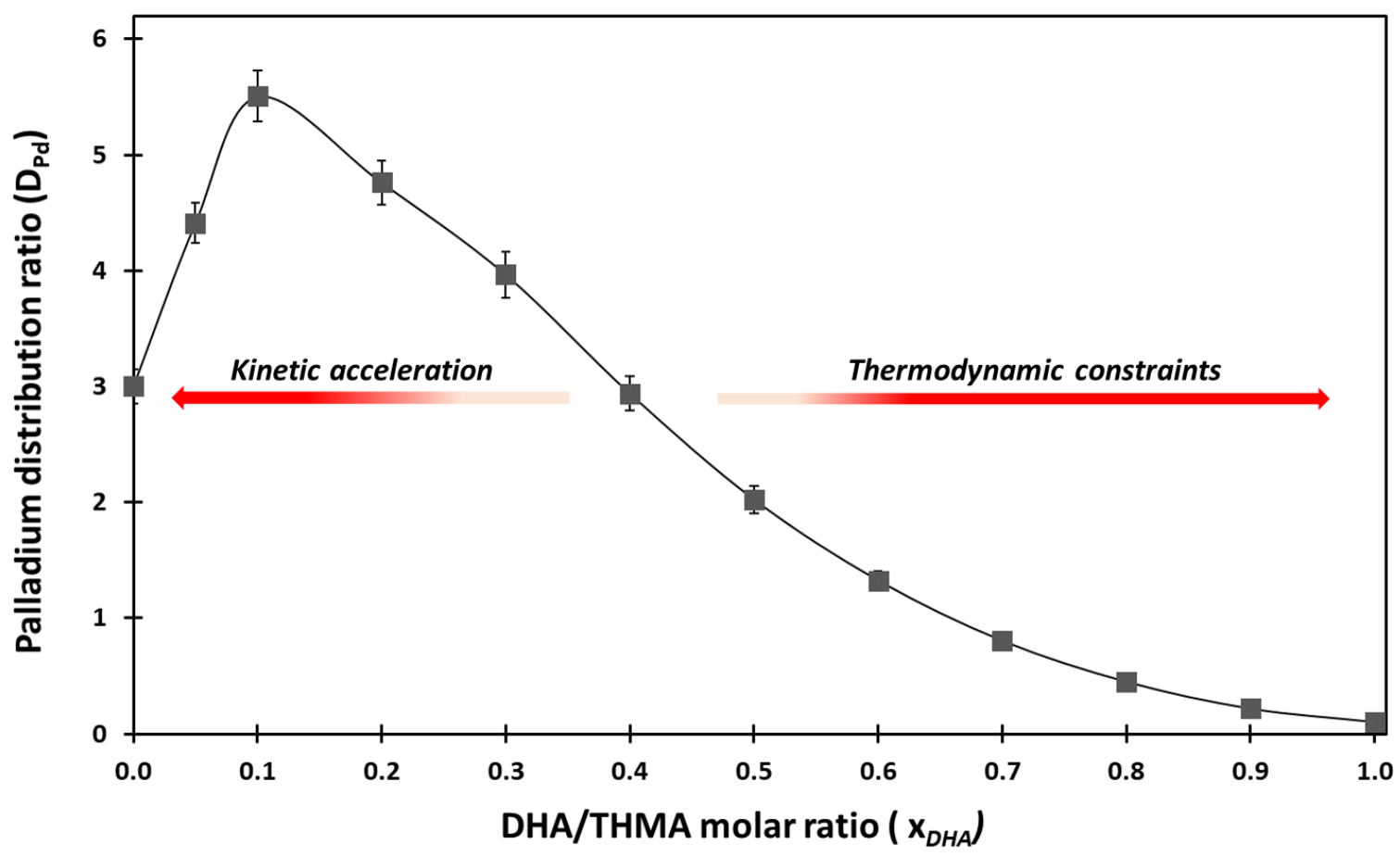

Palladium distribution ratios rapidly rose as the molar ratio of DHA in the organic phase increased, and maximum of $D_{\mathrm{Pd}}=5.5$ was reached for $\mathrm{x}_{D H A}=0.1$. Conversely, by exceeding this limit, palladium distribution ratios decreased continuously, and reached $D_{\mathrm{Pd}}=$ 0.14 for pure DHA. As expected, the Pd(II) extraction strongly relies on sufficient THMA concentration in the organic phase. As long as the THMA content in the solvent is sufficient to enable the extraction of $\mathrm{Pd}(\mathrm{II})$, the contributory effect of DHA is visible. At the maximum point $\left(\mathrm{x}_{D H A}=0.1\right)$, the THMA concentration is still close to $0.2 \mathrm{M}(0.18 \mathrm{M}$ precisely $)$, and the DHA concentration is $0.02 \mathrm{M}$, very close to $10 \mathrm{~mol} \%$ respective to THMA. Afterwards, $\mathrm{Pd}(\mathrm{II})$ extraction efficiency decreases, as the THMA content in the organic phase decreases. Thus, it can be concluded that the benefit of DHA addition is optimum at $10 \mathrm{~mol} \%$. Further addition of DHA does increase the kinetics, but the increase is insufficient to counterbalance loss of efficiency due to lower amount of THMA. Extraction half-time is lowered from 13 min to 10 min upon doubling of the DHA quantity from $10 \mathrm{~mol} \%$ to $20 \mathrm{~mol} \%$. Thus, unless kinetics are the most important parameter, we think that it is not worth adding more than $10 \mathrm{~mol} \%$ DHA. It is worth mentioning here again that these results have been gathered in conditions voluntarily chosen in order to reduce mass transfer during the liquid-liquid extraction process. 
1 The simple set-up we used, and the low quantities of reagents employed enabled a rapid 2 screening of several different conditions. Once optimum conditions are chosen, i) they can be employed for further development in regular conditions, ie. with adequate phase mixing, and ii) the potential kinetics limits have been identified, as well as key parameters to study. The way experimental results are presented is similar to classical studies which evidence synergistic phenomena. In our case, it is clear that mass transfer is limiting, at least on the left side of Figure 6, and that thermodynamic equilibrium is not reached. The results should not be taken as evidence of a synergy. The non-linear behaviour of the extraction results obtained with THMA/DHA mixtures results from an enhancement of the extraction kinetics, counterbalanced by thermodynamic constraints due to poor $\mathrm{Pd}(\mathrm{II})$ extraction with pure DHA. The rise in extraction yield when $\mathrm{x}_{D H A} \leq 0.1\left(\mathrm{x}_{T H M A} \geq 0.9\right)$, where $D_{\text {Pd }}$ with THMA/DHA mixtures are higher than $D_{\mathrm{Pd}}$ with THMA, have been proven to result from enhancement of kinetics by DHA. Then, for the range of $0.1 \leq \mathrm{x}_{D H A} \leq 0.4-0.6$, a decrease in $D_{\mathrm{Pd}}$ was observed, yet they were still higher than $D_{\mathrm{Pd}}$ with THMA at a $0.2 \mathrm{M}$ concentration, thus probably higher than $D_{\mathrm{Pd}}$ at corresponding THMA concentration. The thermodynamical constraints are still partially overcome by the kinetic acceleration. Finally, when $\mathrm{x}_{D H A}>0.6$, the system is entirely governed by thermodynamic limitations. This approach demonstrates that studies of synergism under thermodynamic conditions require proof that there is no kinetic limitation. Kinetics studies are often overlooked, although our results demonstrate that they could be at the origin of an apparent synergy.

\subsection{Extraction of Pd with crude THMA}

As DHA proved to have a beneficial effect on the extraction of $\operatorname{Pd}(\mathrm{II})$ with THMA from nitric acid media, we investigated the possibility to employ unpurified THMA to prepare the extraction solvent. When DHA is employed in excess (more than 2.0 equiv.) respective to diethyl malonate in the synthesis of THMA, the crude reaction mixture only contains residual DHA in addition to THMA. Thus, a batch of crude (unpurified) THMA was evaluated for Pd(II) extraction. This THMA batch was prepared using excess DHA (10 mol\%), with the same synthetic procedure, except that all purification stages (dilution in diethyl ether, $\mathrm{HCl}$ washing, drying over magnesium sulfate and distillation of diethyl ether) were not performed: The synthesis was run solvent free by heating at $180^{\circ} \mathrm{C}$, and the crude mixture was employed directly, after cooling, through dilution of the viscous yellow liquid obtained in toluene.

33 Determination of the molar ratio of residual DHA was performed through integration of 
1 corresponding signal areas in ${ }^{1} \mathrm{H}$ NMR spectrum (see SI, Figure S11). Other diluents can be 2 employed, such as aromatic cuts, eg. Solvesso ${ }^{\mathrm{TM}} 150$ (vide infra). Comparison of the results obtained during Pd(II) extraction between purified THMA and crude THMA in toluene are presented in Table 2:

Table 2. Extraction of $\mathrm{Pd}(\mathrm{II})$ with purified THMA and crude THMA synthesized with an excess of DHA (10 mol\%). THMA concentration $0.2 \mathrm{M}$ in toluene, initial $[\mathrm{Pd}]_{\mathrm{aq}} 500 \mathrm{mg} / \mathrm{L}$, $\left[\mathrm{HNO}_{3}\right]_{\mathrm{aq}} 3 \mathrm{M}$, stirring speed $2000 \mathrm{rpm}, \mathrm{A} / \mathrm{O}=1$.

$$
\begin{array}{cc}
\text { Purified THMA } & \text { Crude THMA } \\
C=0.2 \mathrm{~mol} / \mathrm{L} & C=0.2 \mathrm{~mol} / \mathrm{L}
\end{array}
$$

\begin{tabular}{ccl}
\hline Experiment duration & $24 \mathrm{~h}$ & $1 \mathrm{~h}$ \\
\hline$D_{\mathrm{Pd}}$ & 28 & 34 \\
\hline
\end{tabular}

8

These experiments have been carried out with standard shaking (2000 rpm), and proper emulsification of aqueous and organic phases. No issue was encountered with crude THMA compared to purified THMA during phase disengagement, as the protonated amine does not significantly modify interfacial tension. The results suggest that equilibrium is reached after $1 \mathrm{~h}$ using crude THMA. Thus, the kinetics limitations associated with THMA are successfully overcome by using crude THMA. The extraction performance of the crude THMA was better compared with the purified one (DHA free). Indeed, the palladium distribution ratio increased from 28 when using purified THMA to 34 when using crude THMA.

\subsection{Extraction of $P d(I I)$ and $P t(I V)$ from chloride media}

THMA has proven to be a performing extractant for Pd(II) from nitric acid media. The investigation was further extended to assess the efficiency of THMA in the extraction of $\mathrm{Pd}(\mathrm{II})$ from chloride media. From an industrial application perspective, toluene was replaced by Solvesso ${ }^{\mathrm{TM}} 150$ as diluent. These experiments were carried out with crude THMA using the batch and the procedure described above. THMA concentration was set at 0.2M. THMA showed an efficient extraction of Pd(II) (Table 3). So far, results obtained on Pd(II) extraction with malonamides were mitigated: The best results were obtained in 1,2-dichloroethane at $8 \mathrm{M}$ $\mathrm{HCl},{ }^{57}$ with specific malonamides, with distribution ratios close to 4 . In our hands, extraction of Pd(II) with DBMA from chloride media was very low, so that we employed a sodium 
1 chloride solution as stripping reagent in the Pd purification process we developed. The 2 possibility to extract $\mathrm{Pd}(\mathrm{II})$ with excellent efficiency from chloride media $\left(D_{\mathrm{Pd}}=35.4\right.$ at $[\mathrm{HCl}]$ $3=1 \mathrm{M}$ ) is particularly striking, as only the hydrophobic part of the molecule was modified, the 4 coordinating head is still the same diamide moiety. Using same conditions, $\operatorname{Pd}(\mathrm{II})$ extraction yield with DBMA (0.6M in toluene) was only $2 \%$. Also, extraction of $\mathrm{Pt}(\mathrm{IV})$ was evaluated and gave successful results (Table 3). Distribution ratios of both metals strongly depend on the aqueous hydrochloric acid concentration. The distribution ratio of $\mathrm{Pd}(\mathrm{II})$ decreased from 35.4 to 1 with $\mathrm{HCl}$ concentration increasing from $1 \mathrm{M}$ to $6 \mathrm{M}$, whereas that of $\mathrm{Pt}(\mathrm{IV})$ increased from 10.3 to 27.4. The separation of $\mathrm{Pt}(\mathrm{IV})$ from $\mathrm{Pd}(\mathrm{II})$ is efficient at $6 \mathrm{M}$ aqueous hydrochloric acid concentration, where the separation factor $S_{\mathrm{Pt} / \mathrm{Pd}}$ was 27.4.

Table 3. $\mathrm{Pd}(\mathrm{II})$ and $\mathrm{Pt}(\mathrm{IV})$ distribution ratios $\left(D_{\mathrm{Pd}}\right.$ and $\left.D_{\mathrm{Pt}}\right)$ and $\mathrm{Pt} / \mathrm{Pd}$ selectivity $\left(S_{\mathrm{Pt} / \mathrm{Pd}}\right)$ with crude THMA in Solvesso $^{T M} 150$ from hydrochloric acid media. THMA concentration 0.2M, initial $[\mathrm{Pd}]_{\mathrm{aq}} 500 \mathrm{mg} / \mathrm{L}$, initial $[\mathrm{Pt}]_{\mathrm{aq}} 500 \mathrm{mg} / \mathrm{L}, 1 \mathrm{~h}$ extraction, $\mathrm{A} / \mathrm{O}=1$, stirring speed 2000 rpm.

\begin{tabular}{ccc}
\hline & {$[\mathrm{HCl}]=1 \mathrm{M}$} & {$[\mathrm{HCl}]=6 \mathrm{M}$} \\
\hline$D_{\mathrm{Pd}}$ & 35.4 & 1 \\
$D_{\mathrm{Pt}}$ & 10.3 & 27.4 \\
\hline$S_{\mathrm{Pt} / \mathrm{Pd}}$ & 0.29 & 27.4 \\
\hline
\end{tabular}

Altogether, these preliminary results on platinum group metals (PGM) extraction from chloride media demonstrate the potential interest of THMA for the extraction and purification of these metals. Significant distribution ratios could be obtained in classical conditions, ie. after $1 \mathrm{~h}$, with crude THMA. As a comparison, the extraction of PGM with alkyl sulfides from chloride media require the addition of a fatty amine to obtain acceptable kinetics. It could be worth envisioning the study of the optimum DHA quantity before adapting the technology to PGM separation from chloride media. ${ }^{58}$

It is finally interesting to take into consideration the cost of reagents: DHA is the expensive reagent employed for THMA synthesis (Table 4):

Table 4. Preliminary cost analysis of THMA synthesis. Costs based on Sigma-Aldrich (France) prices available in May 2021, for synthesis grade reagents, in $2.5 \mathrm{~L}$ packaging $(\mathrm{DEM}=$ diethyl malonate $)$.

\begin{tabular}{lllllll}
\hline & $\begin{array}{l}\text { Price } \\
(2.5 \mathrm{~L})\end{array}$ & $\begin{array}{l}\mathrm{M}_{\mathrm{w}} \\
\left(\mathrm{g} \cdot \mathrm{mol}^{-1}\right)\end{array}$ & Density & $\begin{array}{l}\text { Cost } \\
\left(€ \cdot \mathrm{mol}^{-1}\right)\end{array}$ & $\begin{array}{l}\text { Equi } \\
\text { v. }\end{array}$ & $\begin{array}{l}\text { Cost for synthesis of } \\
1 \text { mole THMA }\end{array}$ \\
\hline DEM & $117 €$ & 160.17 & 1.15 & 6.5 & 1 & $6.5 €$
\end{tabular}




$\begin{array}{lllllll}\text { DHA } & 280 € & 185.35 & 0.795 & 26.1 & 2 & 52.2 € \\ \text { THMA } & \text { n.a. } & 438.73 & & & & 58.7 €\end{array}$

Thus, each 10 mol\% added DHA will increase the cost of prepared THMA by $4.5 \%$ $(2.6 €)$. This cost analysis is preliminary, only based on reagents costs. The results are indicative, they should only be considered in comparison with other reagents available from the same supplier in same packaging. For instance, tributyl phosphate (TBP) can be purchased in $2.5 \mathrm{~L}$ packaging for $137 €$ from Sigma-Aldrich (France), thus at a $56 € / \mathrm{kg}$ price, to be compared with the $134 € / \mathrm{kg}$ price for THMA based on reagents employed. In other words, the cost for THMA is expected to be in the same order of magnitude as that of TBP. From same supplier, and based on same packaging, dioctyl sulfide (DOS) is 10-20 times as expensive as TBP. Thus, THMA is one order of magnitude cheaper than DOS, an extracting molecule than can be employed at industrial scale for PGM refining. Altogether, this analysis and the obtained results suggest that THMA should be investigated with careful attention for PGM refining.

\section{Conclusion}

Tetrahexylmalonamide (THMA) is a performing extracting molecule for $\mathrm{Pd}(\mathrm{II})$ extraction from nitrate and from chloride media. Although the pure molecule displays slow kinetics, the possibility to accelerate extraction through the use of excess dihexylamine (DHA) enabled to propose a formulation of extracting molecules in order to prepare a performing extraction solvent. Furthermore, this formulation can be directly obtained after reaction between the two reagents needed to prepare THMA, diethyl malonate (DEM) and DHA. We demonstrated that the crude reaction product can be employed directly for solvent extraction, without work-up nor purification, after sole dilution in the required diluent (eg. Solvesso $^{T M} 150$ ), as there is no organic solvent employed for the synthesis. This approach is particularly interesting as both reagents, DEM and THA, are registered chemicals, easy to handle, and not flammable. Consequently, there is no regulation issue with the use of THMA as long as it is prepared in situ. Extraction performances were extended to $\mathrm{Pd}(\mathrm{II})$ and $\mathrm{Pt}(\mathrm{IV})$ extraction from chloride media. Potential applications of the proposed extraction solvent in platinum group metals (PGM) refining is underway. Also, deep understanding of the impact of the molecular topology on extraction outcome will be continued. 
The kinetics study was performed via simple experimental models. By deliberately

2 lowering the stirring speed, we demonstrated that relevant data can be acquired. A deeper 3 understanding of the kinetics phenomena involved, and the determination of precise absolute 4 mass transfer rate constants require more complex devices (single drop technique, rotating 5 membrane, cell with controlled interface) that cannot be employed for intensive screening. 6 Our approach enabled to precise the importance of different parameters (DHA concentration, 7 THMA concentration, aqueous $\mathrm{HNO}_{3}$ and $\mathrm{Pd}(\mathrm{II})$ concentrations...) so that dimensioning of 8 adapted kinetics studies will be straightforward. More generally, the proposed method is 9 worth considering when kinetics limitations are suspected. Finally, we would like to point attention to possible artefacts and pitfalls related to misinterpretation of solvent extraction

11 results when kinetics are not properly checked: Although the results obtained on THMA/DHA 12 mixtures sound like synergism, they should not be interpreted this way.

\section{Acknowledgements}

15 The authors thank the Commissariat à l'Energie Atomique et aux Energies alternatives (CEA) 16 that has funded and supported this work. 


\section{References}

1. Fröhlich P, Lorenz T, Martin G, Brett B, Bertau M. Valuable Metals-Recovery Processes, Current Trends, and Recycling Strategies. Angew Chem Int Ed. 2017;56(10):2544-2580. doi:10.1002/anie.201605417

2. Jasiński D, Meredith J, Kirwan K. The life cycle impact for platinum group metals and lithium to 2070 via surplus cost potential. Int J Life Cycle Assess. 2018;23(4):773-786. doi:10.1007/s11367-017-1329-4

3. Ilyas S, Srivastava RR, Kim H, Cheema HA. Hydrometallurgical recycling of palladium and platinum from exhausted diesel oxidation catalysts. Separation and Purification Technology. 2020;248:117029. doi:10.1016/j.seppur.2020.117029

4. Sverdrup HU, Ragnarsdottir KV. A system dynamics model for platinum group metal supply, market price, depletion of extractable amounts, ore grade, recycling and stocks-inuse. Resources, Conservation and Recycling. 2016;114:130-152. doi:10.1016/j.resconrec.2016.07.011

5. Cowley A. Johnson Matthey Pgm Market Report February 2019.; 2019. Accessed May 13, 2019. http://www.platinum.matthey.com/documents/newitem/pgm\%20market\%20reports/pgm_market_report_february_2019.pdf

6. Mineral Industry Surveys, Platinum-Group Metals in February 2021. Published online 2021. https://www.usgs.gov/centers/nmic/platinum-group-metals-statistics-andinformation

7. Islam A, Ahmed T, Awual MdR, et al. Advances in sustainable approaches to recover metals from e-waste-A review. Journal of Cleaner Production. 2020;244:118815. doi:10.1016/j.jclepro.2019.118815

8. Chauhan G, Jadhao PR, Pant KK, Nigam KDP. Novel technologies and conventional processes for recovery of metals from waste electrical and electronic equipment: Challenges \& opportunities - A review. Journal of Environmental Chemical Engineering. 2018;6(1):1288-1304. doi:10.1016/j.jece.2018.01.032

9. Gu F, Summers PA, Hall P. Recovering materials from waste mobile phones: Recent technological developments. Journal of Cleaner Production. 2019;237:117657. doi:10.1016/j.jclepro.2019.117657

10. Iş1ldar A, Rene ER, van Hullebusch ED, Lens PNL. Electronic waste as a secondary source of critical metals: Management and recovery technologies. Resources, Conservation and Recycling. 2018;135:296-312. doi:10.1016/j.resconrec.2017.07.031

11. Padamata SK, Yasinskiy AS, Polyakov PV, Pavlov EA, Varyukhin DYu. Recovery of Noble Metals from Spent Catalysts: A Review. Metall Mater Trans B. 2020;51(5):24132435. doi:10.1007/s11663-020-01913-w

12. Ashiq A, Kulkarni J, Vithanage M. Hydrometallurgical Recovery of Metals From Ewaste. In: Electronic Waste Management and Treatment Technology. Elsevier; 2019:225246. doi:10.1016/B978-0-12-816190-6.00010-8 
13. Narita H, Suzuki T, Motokawa R. Recent Research in Solvent Extraction of Platinum Group Metals. JJapan InstMetals. 2017;81(4):157-167. doi:10.2320/jinstmet.JE201604

14. Kaya M. Recovery of metals and nonmetals from electronic waste by physical and chemical recycling processes. Waste Management. 2016;57:64-90. doi:10.1016/j.wasman.2016.08.004

15. Poirot R, Bourgeois D, Meyer D. Palladium Extraction by a Malonamide Derivative (DMDOHEMA) from Nitrate Media: Extraction Behavior and Third Phase Characterization. Solvent Extraction and Ion Exchange. 2014;32(5):529-542. doi:10.1080/07366299.2014.908587

16. Wang J, Xu W, Liu H, Yu F, Wang H. Extractant structures and their performance for palladium extraction and separation from chloride media: A review. Minerals Engineering. 2021;163:106798. doi:10.1016/j.mineng.2021.106798

17. Lee J, Kurniawan, Hong H-J, Chung KW, Kim S. Separation of platinum, palladium and rhodium from aqueous solutions using ion exchange resin: A review. Separation and Purification Technology. 2020;246:116896. doi:10.1016/j.seppur.2020.116896

18. Zhang A, Xue W, Dong X. Development of palladium separation process from nitric acid medium utilizing a new hybrid multi-nitrogen adsorbent. Separation and Purification Technology. 2017;189:220-228. doi:10.1016/j.seppur.2017.07.057

19. Wu F, Yang C, Liu Y, Hu S, Ye G, Chen J. Novel polyazamacrocyclic receptor impregnated macroporous polymeric resins for highly efficient capture of palladium from nitric acid media. Separation and Purification Technology. 2020;233:115953. doi:10.1016/j.seppur.2019.115953

20. Manchanda V. Amides and diamides as promising extractants in the back end of the nuclear fuel cycle: An overview. Separation and Purification Technology. 2004;35(2):85103. doi:10.1016/j.seppur.2003.09.005

21. Costa MC, Assunção A, da Costa AMR, Nogueira C, Paiva AP. Liquid-Liquid Extraction of Platinum from Chloride Media by $N, N^{\prime}$-Dimethyl- $N, N^{\prime}-$

Dicyclohexyltetradecylmalonamide. Solvent Extraction and Ion Exchange. 2013;31(1):12-23. doi:10.1080/07366299.2012.700588

22. Costa MC, Almeida R, Assunção A, Rosa da Costa AM, Nogueira C, Paiva AP. N , N 'tetrasubstituted succinamides as new molecules for liquid-liquid extraction of $\mathrm{Pt}(\mathrm{IV})$ from chloride media. Separation and Purification Technology. 2016;158:409-416. doi:10.1016/j.seppur.2015.12.035

23. Narita H, Morisaku K, Tamura K, et al. Extraction Properties of Palladium(II) in HCl Solution with Sulfide-Containing Monoamide Compounds. Ind Eng Chem Res. 2014;53(9):3636-3640. doi:10.1021/ie404363b

24. Matsumiya M, Song Y, Tsuchida Y, Sasaki Y. Separation of palladium by solvent extraction with methylamino-bis-N,N-dioctylacetamide and direct electrodeposition from loaded organic phase. Separation and Purification Technology. 2020;234:115841. doi:10.1016/j.seppur.2019.115841 
25. Poirot R, Le Goff X, Diat O, Bourgeois D, Meyer D. Metal Recognition Driven by Weak Interactions: A Case Study in Solvent Extraction. ChemPhysChem. 2016;17(14):21122117. doi:10.1002/cphc.201600305

26. Mastretta R, Poirot R, Bourgeois D, Meyer D. Palladium Isolation and Purification from Nitrate Media: Efficient Process Based on Malonamides. Solvent Extraction and Ion Exchange. 2019;37(2):140-156. doi:10.1080/07366299.2019.1630073

27. Bourgeois D, Lacanau V, Mastretta R, Contino-Pépin C, Meyer D. A simple process for the recovery of palladium from wastes of printed circuit boards. Hydrometallurgy. 2020;191:105241. doi:10.1016/j.hydromet.2019.105241

28. Dul M-C, Braibant B, Dourdain S, Pellet-Rostaing S, Bourgeois D, Meyer D. Perfluoroalkyl- vs alkyl substituted malonamides: Supramolecular effects and consequences for extraction of metals. Journal of Fluorine Chemistry. 2017;200:59-65. doi:10.1016/j.jfluchem.2017.06.001

29. Dul M-C, Bourgeois D, Maynadié J, Meyer D. Synthesis of fluorinated malonamides and use in L/L extraction of f-elements. Tetrahedron Letters. 2013;54(46):6271-6274. doi:10.1016/j.tetlet.2013.09.031

30. Braibant B, Le Goff X, Bourgeois D, Meyer D. Impact of the Long-Range Electronic Effect of a Fluorous Ponytail on Metal Coordination during Solvent Extraction. Chemphyschem. 2017;18(24):3583-3594. doi:10.1002/cphc.201701030

31. Mowafy EA, Aly HF. Extraction Behaviors of Trivalent Lanthanides from Nitrate Medium by Selected Substituted Malonamides. Solvent Extraction and Ion Exchange. 2006;24(5):677-692. doi:10.1080/07366290600762322

32. McNamara BK, Lumetta GJ, Rapko BM. Extraction of Europium(III) ion with tetrahexylmalonamides. Solvent Extraction and Ion Exchange. 1999;17(6):1403-1421. doi:10.1080/07366299908934655

33. Sasaki Y, Tachimori S. Extraction of Actinides(III), (IV), (V), (VI), and Lanthanides(III) by structurally tailored diamides. Solvent Extraction and Ion Exchange. 2002;20(1):2134. doi:10.1081/SEI-100108822

34. Serrano-Purroy D, Baron P, Christiansen B, Malmbeck R, Sorel C, Glatz J-P. Recovery of minor actinides from HLLW using the DIAMEX process. Radiochimica Acta. 2005;93(6). doi:10.1524/ract.93.6.351.65642

35. Modolo G, Vijgen H, Serrano- Purroy D, et al. DIAMEX Counter- Current Extraction Process for Recovery of Trivalent Actinides from Simulated High Active Concentrate. Separation Science and Technology. 2007;42(3):439-452. doi:10.1080/01496390601120763

36. Bao M, Sun G-X. Extraction of uranium(VI) with $\mathrm{N}, \mathrm{N}, \mathrm{N}^{\prime}, \mathrm{N}^{\prime}$-tetrabutylmalonamide and N,N,N',N'-tetrahexylmalonamide. J Radioanal Nucl Chem. 1998;231(1-2):203-205. doi:10.1007/BF02388035 
37. Lumetta GJ, McNamara BK, Rapko BM, et al. Synthesis and characterization of monoand bis-(tetraalkylmalonamide)uranium(VI) complexes. Inorganica Chimica Acta. 2000;309(1-2):103-108. doi:10.1016/S0020-1693(00)00253-X

38. Swain B, Jeong J, Kim S, Lee J. Separation of platinum and palladium from chloride solution by solvent extraction using Alamine 300. Hydrometallurgy. 2010;104(1):1-7. doi:10.1016/j.hydromet.2010.03.013

39. Lee J-Y, Rajesh Kumar J, Kim J-S, Park H-K, Yoon H-S. Liquid-liquid extraction/separation of platinum(IV) and rhodium(III) from acidic chloride solutions using tri-iso-octylamine. Journal of Hazardous Materials. 2009;168(1):424-429. doi:10.1016/j.jhazmat.2009.02.056

40. Lee J-Y, Kumar JR, Kim J-S, Kim D-J, Yoon H-S. Extraction and separation of $\mathrm{Pt}(\mathrm{IV}) / \mathrm{Rh}$ (III) from acidic chloride solutions using Aliquat 336. Journal of Industrial and Engineering Chemistry. 2009;15(3):359-364. doi:10.1016/j.jiec.2008.12.006

41. Cieszynska A, Wieczorek D. Extraction and separation of palladium(II), platinum(IV), gold(III) and rhodium(III) using piperidine-based extractants. Hydrometallurgy. 2018;175:359-366. doi:10.1016/j.hydromet.2017.12.019

42. Belova VV, Khol'kin AI, Zhidkova TI. Extraction of platinum-group metals from chloride solutions by salts of quaternary ammonium bases and binary extractants. Theoretical Foundations of Chemical Engineering. 2007;41(5):743-751. doi:10.1134/S004057950705051X

43. Nguyen TH, Sonu CH, Lee MS. Separation of platinum(IV) and palladium(II) from concentrated hydrochloric acid solutions by mixtures of amines with neutral extractants. Journal of Industrial and Engineering Chemistry. 2015;32:238-245. doi:10.1016/j.jiec.2015.08.022

44. Raju B, Kumar JR, Lee J-Y, Kwonc H-S, Kantam ML, Reddy BR. Separation of platinum and rhodium from chloride solutions containing aluminum, magnesium and iron using solvent extraction and precipitation methods. Journal of Hazardous Materials. 2012;227228:142-147. doi:10.1016/j.jhazmat.2012.05.025

45. Inoue K, Furusawa T, Nagamatsu I, Baba Y, Yoshizuka K. Solvent extraction of palladium (II) with trioctylmethylammonium chloride. Solvent Extraction and Ion Exchange. 1988;6(5):755-769. doi:10.1080/07366298808917964

46. Jaree A, Khunphakdee N. Separation of concentrated platinum(IV) and rhodium(III) in acidic chloride solution via liquid-liquid extraction using tri-octylamine. Journal of Industrial and Engineering Chemistry. 2011;17(2):243-247. doi:10.1016/j.jiec.2011.02.013

47. Szymanowski J, Bauer D, Cote G, Prochaska K. The surface activity of triisooctylamine and the mechanism of palladium (II) extraction by dihexyl sulphide in the presence of triisooctylamine. Journal of Chemical Technology \& Biotechnology. 2007;48(1):1-15. doi:10.1002/jctb.280480102 
48. Al-Bazi SJ, Freiser H. Phase transfer catalysis in palladium extraction by 1-(2pyridylazo)-2-naphtol (PAN). Solvent Extraction and Ion Exchange. 1987;5(6):997-1016. doi:10.1080/07366298708918606

49. Rong Q, Preiser H. The catalytic effect of quaternary ammonium salt On the Extraction of Palladium(II) With 2-Hydroxy-5-Nonyi-Benzophenone Oxime(LIX 65N) In HeptaneChloroform Solvents. Solvent Extraction and Ion Exchange. 1987;5(5):923-937. doi:10.1080/07366298708918601

50. Szymanowski J, Cote G. Catalytic effects in solvent extraction. Journal of Radioanalytical and Nuclear Chemistry Articles. 1994;183(1):49-58. doi:10.1007/BF02043115

51. Mezhov EA, Kuchumov VA, Druzhenkov VV. Study of Extraction of Palladium from Nitric Acid Solutions with Nitrogen-Containing Compounds, as Applied to Recovery of Fission Palladium from Spent Nuclear Fuel of Nuclear Power Plants: 1. Extraction and Backwashing Conditions. 2002;44(2):6.

52. Mikulaj V, Macášek F, Rajec P. Simultaneous extraction of palladium and technetium from nitrate solutions with tri-n-octylamine. Journal of Radioanalytical Chemistry. 1979;51(1):55-62. doi:10.1007/BF02519923

53. Zhang A, Wanyan G, Kumagai M. Extraction Chemistry of Palladium(II). Mechanism of Antagonistic Synergistic Extraction of Palladium By A 4-Aroyl Derivative of 1-phenyl-3Methyl-Pyrazolone-5- one and Trialkylamine of High Molecular Weight. Transition Metal Chemistry. 2004;29(5):571-576. doi:10.1023/B:TMCH.0000037532.41519.61

54. Smith EL, Page JE. The acid-binding properties of long-chain aliphatic amines. $J$ Chem Technol Biotechnol. 1948;67(2):48-51. doi:10.1002/jctb.5000670203

55. Tsujino T, Ishihara T. Effect of Temperature on the Extraction of Nitric Acid, Uranium and Fission Products with Tri- $n$-Octyl Amine. Journal of Nuclear Science and Technology. 1967;4(7):353-360. doi:10.1080/18811248.1967.9732765

56. Lloyd PJ, Mason EA. Extraction of Hexavalent Uranium by Trilaurylamine Nitrate. The Journal of Physical Chemistry. 1964;68(11):3120-3129. doi:10.1021/j100793a006

57. Paiva AP, Carvalho GI, Costa MC, Costa AMR da, Nogueira C. The solvent extraction performance of N,N'-dimethyl-N,N'-dibutylmalonamide towards platinum and palladium in chloride media. Separation Science and Technology. 2014;49(7):966-973. doi:10.1080/01496395.2013.878721

58. Malik P, Paiva AP. A Novel Solvent Extraction Route for the Mutual Separation of Platinum, Palladium, and Rhodium in Hydrochloric Acid Media. Solvent Extraction and Ion Exchange. 2010;28(1):49-72. doi:10.1080/07366290903408599 


\section{Supporting information}

2

3

4 Solvent extraction of Palladium(II) using malonamides: A

5 performing molecular system established through a

6 detailed study of extraction kinetics.

7 Sayed-Ali Moussaoui, ${ }^{a}$ Anne Lélias, ${ }^{b}$ Bertrand Braibant, ${ }^{a}$ Daniel Meyer, ${ }^{a}$ Damien

8 Bourgeois $^{\mathrm{a}}$

9 a Institut de Chimie Séparative de Marcoule, ICSM, CEA, CNRS, ENSCM, Univ 10 Montpellier, BP 17171, Marcoule, 30207 Bagnols-sur-Cèze, France.

$11{ }^{b}$ DMRC/SPTC/LCIS, CEA Marcoule, BP 17171, Marcoule, 30207 Bagnols-sur-Cèze, 12 France.

13 damien.bourgeois@umontpellier.fr 
1 Figure S1: Experimental set-up for the synthesis of $N, N, N^{\prime}, N^{\prime}-$

2 tetrahexylmalonamide.

3 Reaction:

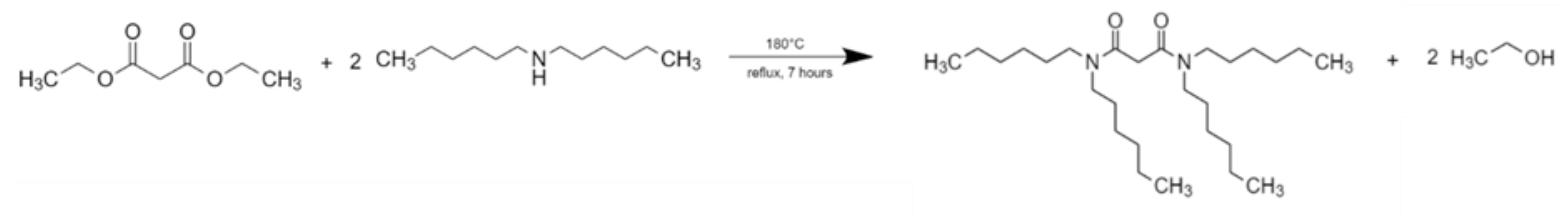

5 Set-up:

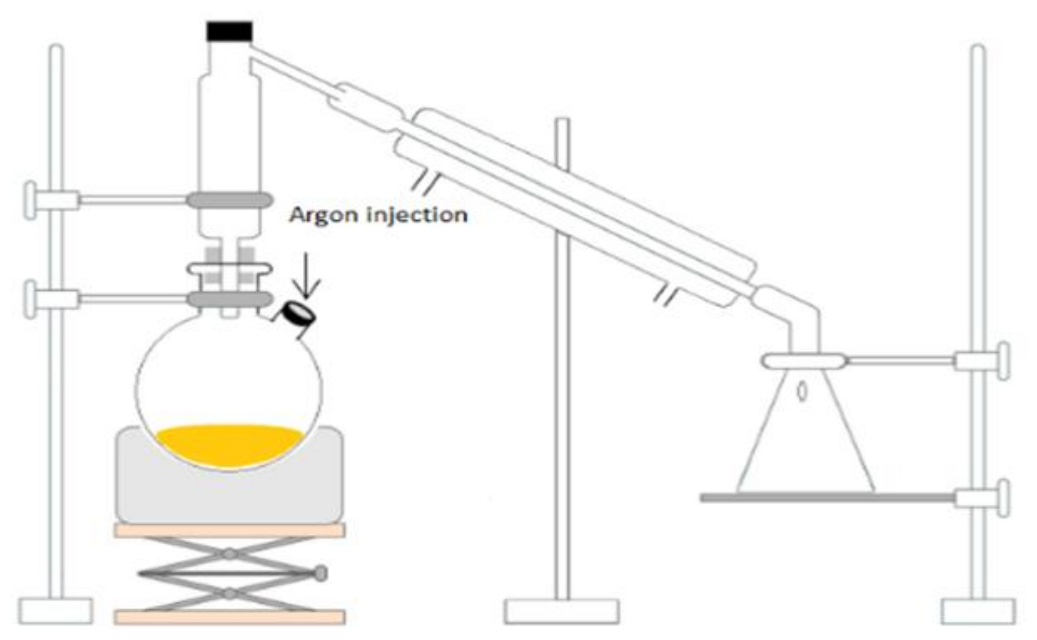

6

7

8 Figure S2: Progress of $\mathrm{Pd}(\mathrm{II})$ extraction with $0.2 \mathrm{M}$ THMA in toluene as a 9 function of time. $\left[\mathrm{HNO}_{3}\right]_{\mathrm{aq}} 3 \mathrm{M}$, initial $[\mathrm{Pd}]_{\mathrm{aq}} 500 \mathrm{mg} / \mathrm{L}, \mathrm{A} / \mathrm{O}=1$, stirring speed $101200 \mathrm{rpm}$.

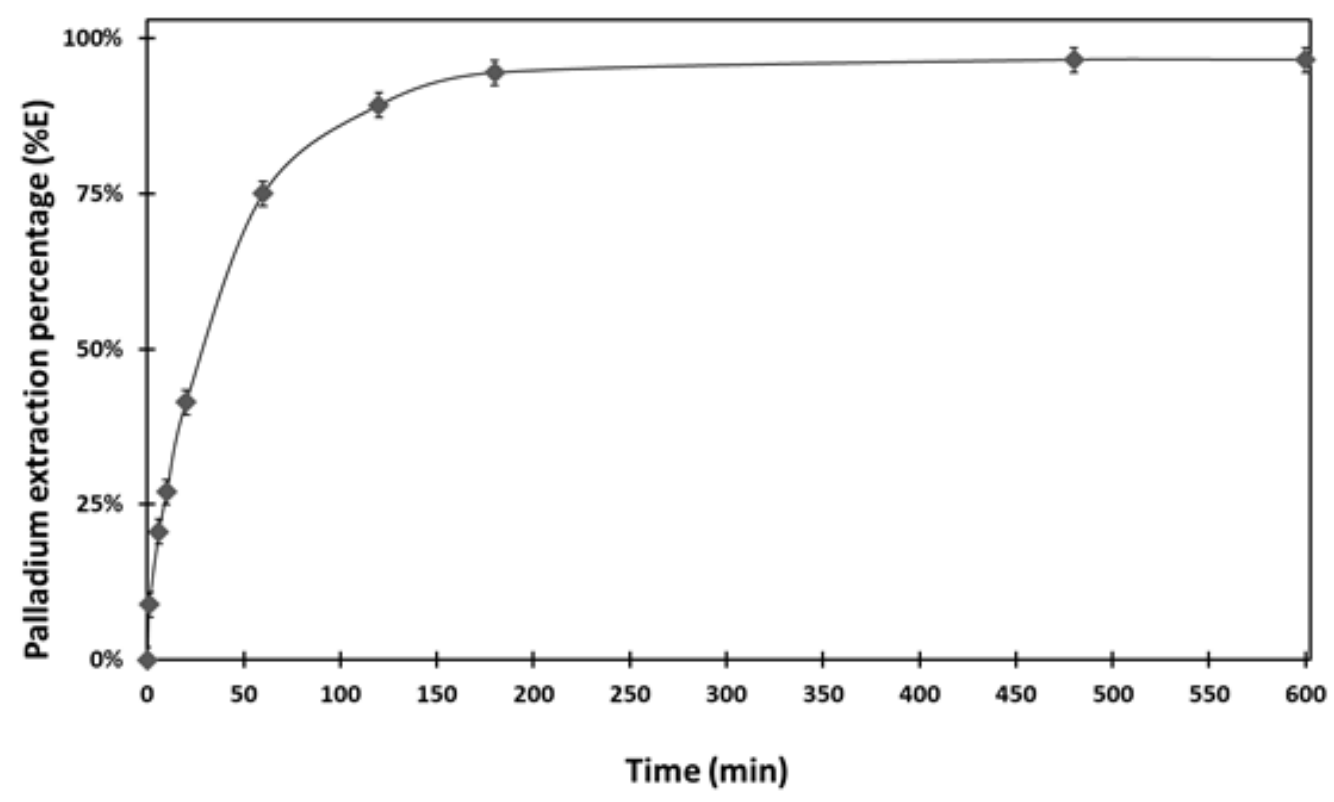


1 Figure S3: ${ }^{1} \mathrm{H}$ NMR and ${ }^{13} \mathrm{C}$ NMR spectra of THMA (400 MHz, $100 \mathrm{MHz}$, 2 solvent $\mathrm{CDCl}_{3}$ ).
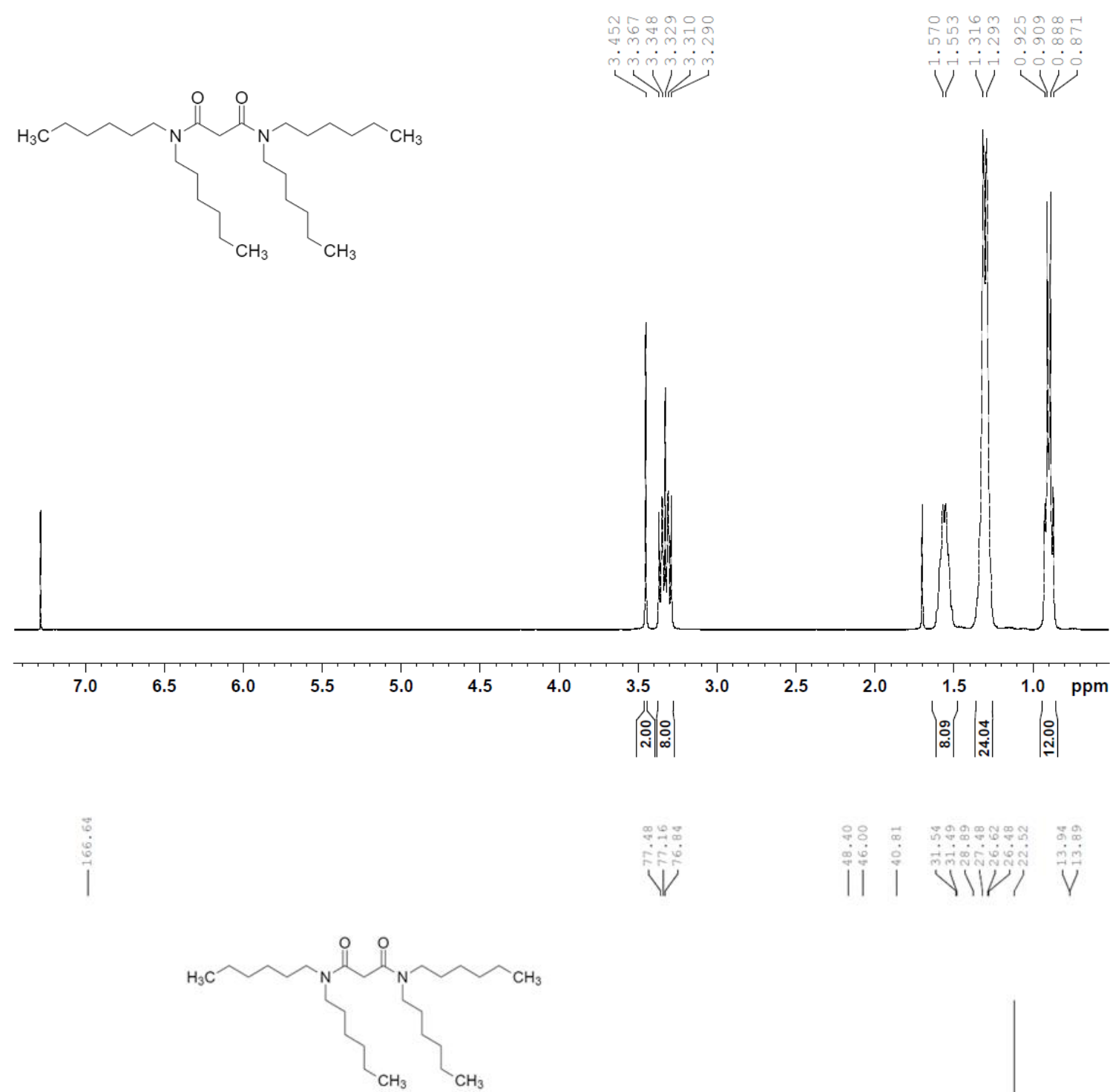
1 Figure S4: FT-IR spectrum of THMA.

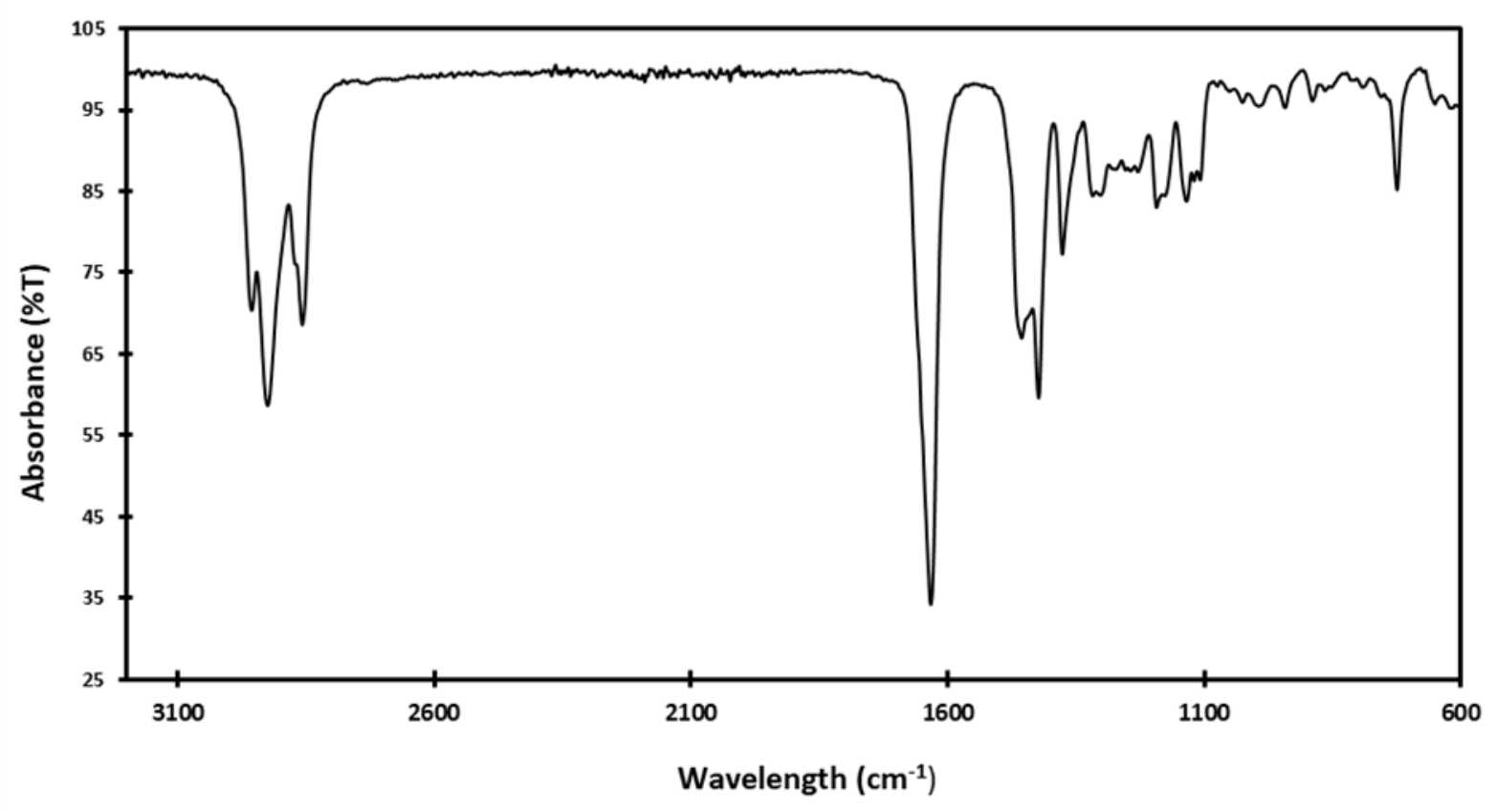

3

4 Table S1: FTIR vibrations of THMA.

\begin{tabular}{cc}
\hline Wavenumber $/ \mathrm{cm}^{-1}$ & Assignment \\
\hline $2850 \mathrm{~cm}^{-1}-2927 \mathrm{~cm}^{-1}$ & $\vee \mathrm{CH}_{2}$ (stretching) \\
$1634 \mathrm{~cm}^{-1}$ & $\vee \mathrm{C}=\mathrm{O}$ (stretching) \\
$1456 \mathrm{~cm}^{-1}$ & $\vee \mathrm{CH}_{2}$ (bending) \\
$1420 \mathrm{~cm}^{-1}$ & $v \mathrm{C}-\mathrm{N}$ (stretching) \\
$1376 \mathrm{~cm}^{-1}$ & $v \mathrm{C}-\mathrm{H}$ (bending) \\
\hline
\end{tabular}

5

6

7

8

9

10

11

12

13 
1 Figure S5: Effect of stirring speed on the Pd(II) extraction with 0.2M THMA in 2 toluene. $\left[\mathrm{HNO}_{3}\right] 3 \mathrm{M}$, initial $[\mathrm{Pd}]_{\mathrm{aq}} 500 \mathrm{mg} / \mathrm{L}, 1 \mathrm{~min}$ of extraction.

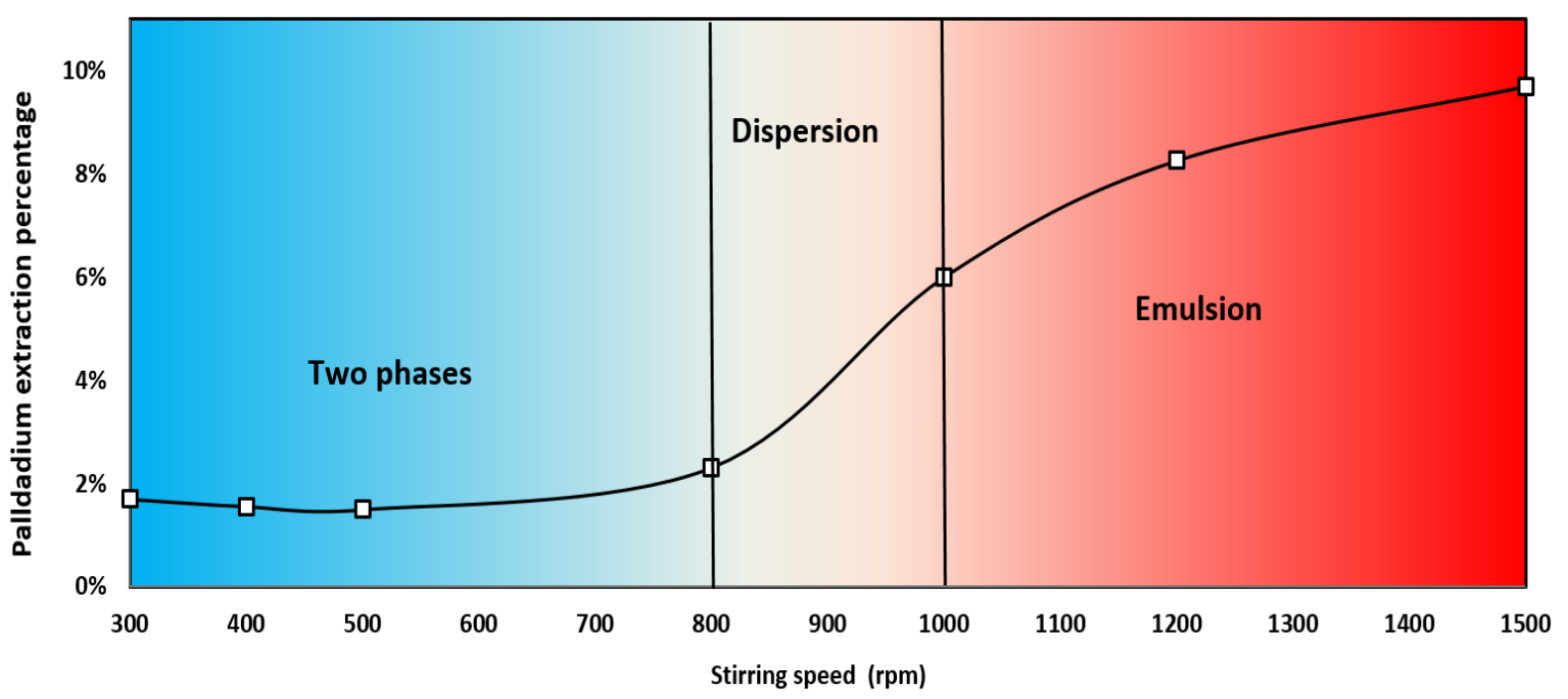

7 Figure S6: $\mathrm{Pd}(\mathrm{II})$ distribution ratio with $0.2 \mathrm{M}$ THMA in toluene with added 8 DHA after $1 \mathrm{~h}$ of extraction. DHA molar percentage $0 \mathrm{~mol} \%$ to $100 \mathrm{~mol} \%$ 9 respective to THMA, initial $[\mathrm{Pd}]_{\mathrm{aq}} 500 \mathrm{mg} / \mathrm{L},\left[\mathrm{HNO}_{3}\right]_{\mathrm{aq}} 3 \mathrm{M}, \mathrm{A} / \mathrm{O}=1$, stirring 10 speed $1200 \mathrm{rpm}$.

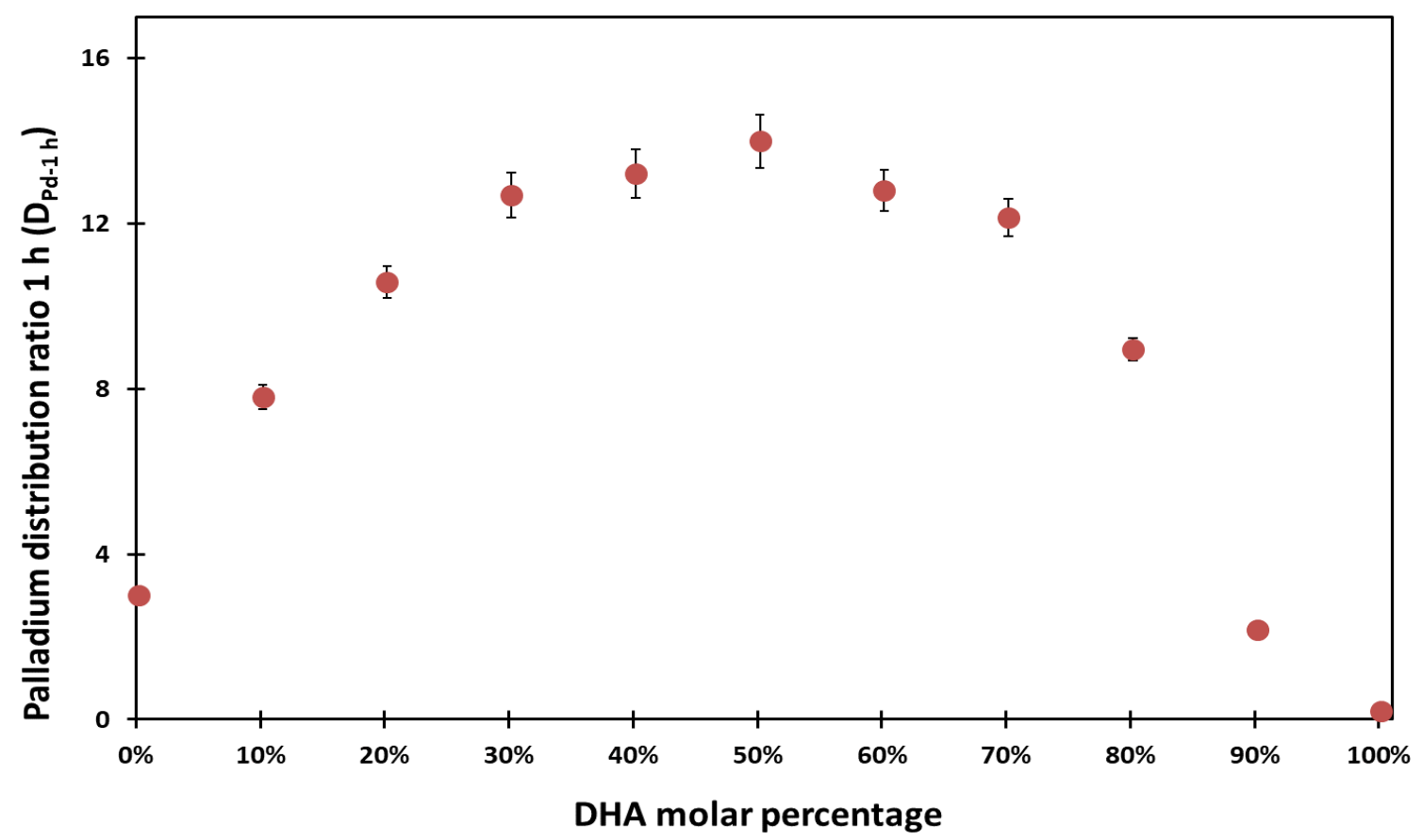


1 Figure S7: Variation of the interfacial tension upon addition of DHA in the 2 organic phase. $0.2 \mathrm{M}$ THMA in toluene, DHA molar percentage $0 \mathrm{~mol} \%$ to $350 \mathrm{~mol} \%$ respective to THMA, $\left[\mathrm{HNO}_{3}\right]_{\text {aq }} 3 \mathrm{M}, \mathrm{T}=23^{\circ} \mathrm{C}$.

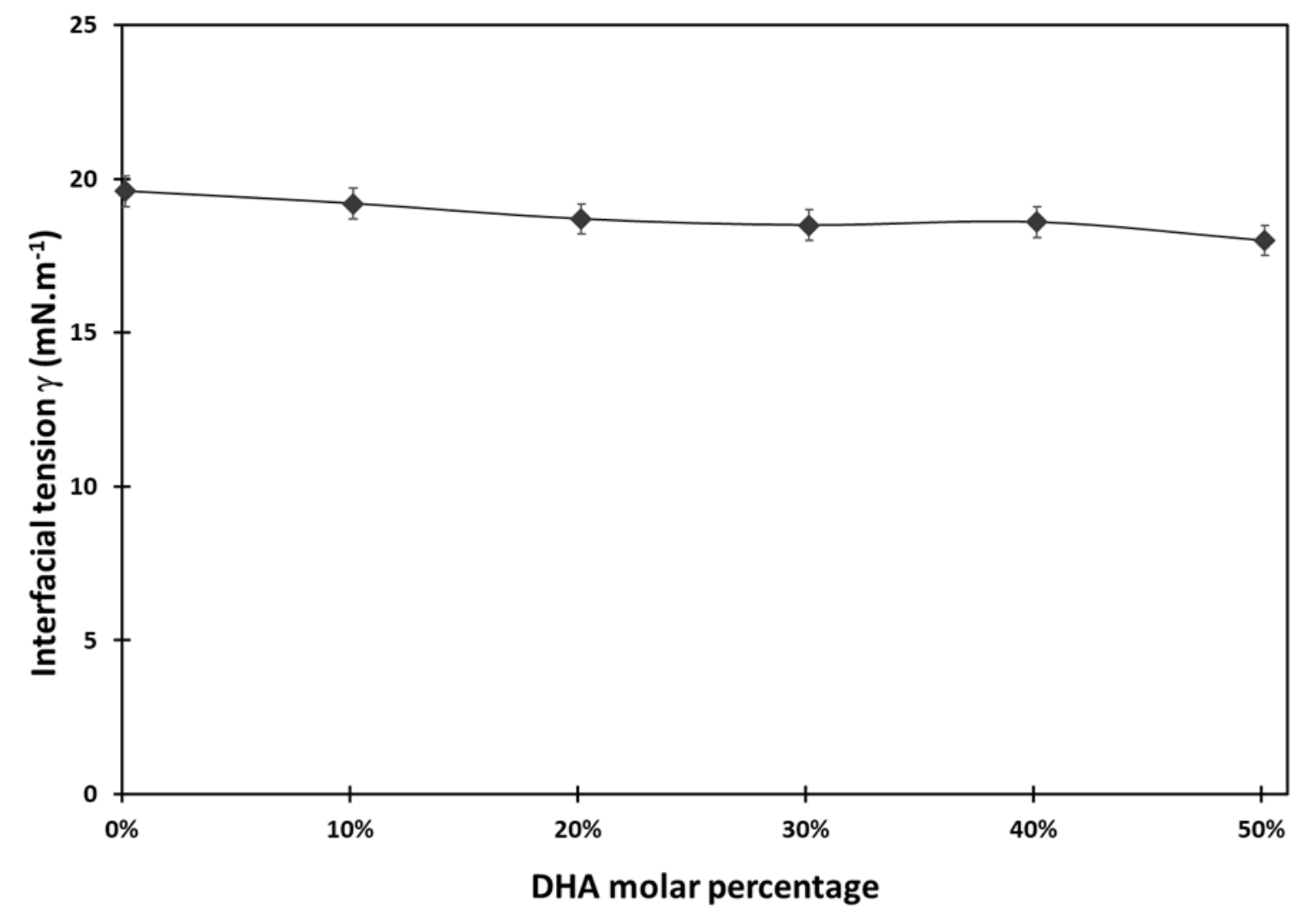

8 Table S2: Variation of the aqueous concentration of $\mathrm{Pd}(\mathrm{II})$ at equilibrium (24 h) 9 after extraction with 0.2M THMA in toluene with added DHA. DHA molar 10 percentage $0 \mathrm{~mol} \%$ to $50 \mathrm{~mol} \%$ respective to THMA.

\begin{tabular}{|c|c|c|c|}
\hline $\begin{array}{c}\text { DHA molar } \\
\text { percentage }\end{array}$ & $\boldsymbol{P d _ { \text { aq,eq } } ( \boldsymbol { m g } . \boldsymbol { L } ^ { - \mathbf { 1 } } )}$ & $\boldsymbol{k}_{\boldsymbol{o b s}}\left(\mathbf{m i n}^{-\mathbf{1}}\right)$ & $\mathbf{t}_{\mathbf{1 / 2}}(\mathbf{m i n})$ \\
\hline $\mathbf{0 ~ m o l \%}$ & 16.7 & 0.028 & 25 \\
\hline $\mathbf{1 0} \mathbf{~ m o l \%}$ & 15.2 & 0.052 & 13 \\
\hline $\mathbf{2 0} \mathbf{~ m o l \%}$ & 13.2 & 0.070 & 10 \\
\hline $\mathbf{3 0} \mathbf{~ m o l \%}$ & 14.7 & 0.079 & 9 \\
\hline $\mathbf{4 0} \mathbf{m o l \%}$ & 13.6 & 0.104 & 7 \\
\hline $\mathbf{5 0} \mathbf{~ m o l \%}$ & 15.4 & 0.116 & 6 \\
\hline
\end{tabular}

11 
1 Figure S8: Evolution of observed rate constant $k_{\mathrm{obs}}$ of $\mathrm{Pd}(\mathrm{II})$ extraction with 2 0.2M THMA in toluene from aqueous $3 \mathrm{M} \mathrm{HNO}_{3}$ solution according to the 3 added DHA quantity. Initial $[\mathrm{Pd}]_{\mathrm{aq}} 500 \mathrm{mg} / \mathrm{L},\left[\mathrm{HNO}_{3}\right]_{\mathrm{aq}} 3 \mathrm{M}$, stirring speed $4 \quad 1200 \mathrm{rpm}$.

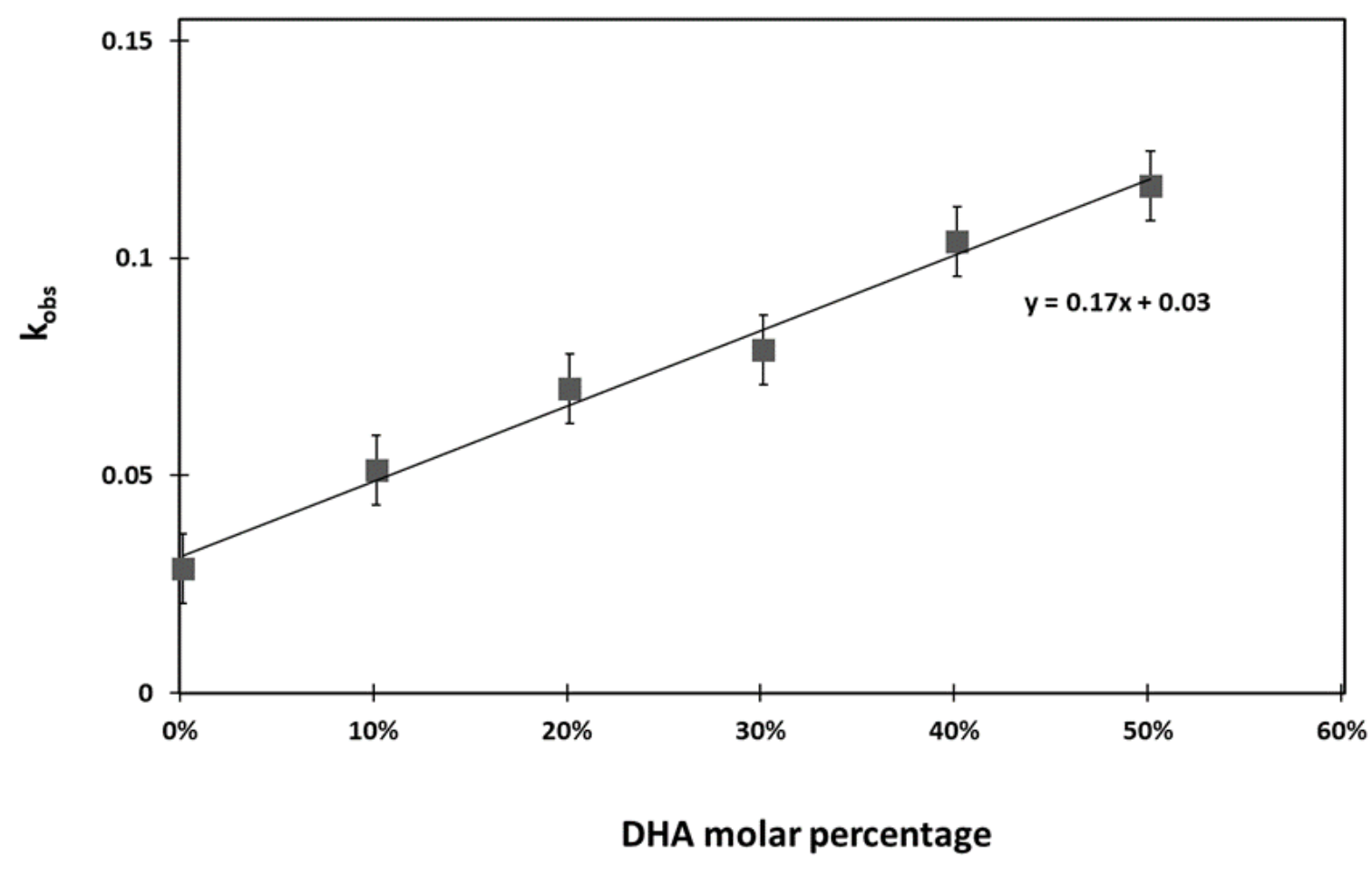

6

7 Figure S9: Effect of $\mathrm{HNO}_{3}$ on $\mathrm{Pd}(\mathrm{II})$ extraction with 0.2M THMA in toluene at 8 equilibrium $(24 \mathrm{~h})$. Initial $[\mathrm{Pd}]_{\mathrm{aq}} 500 \mathrm{mg} / \mathrm{L}, \mathrm{A} / \mathrm{O}=1$. 


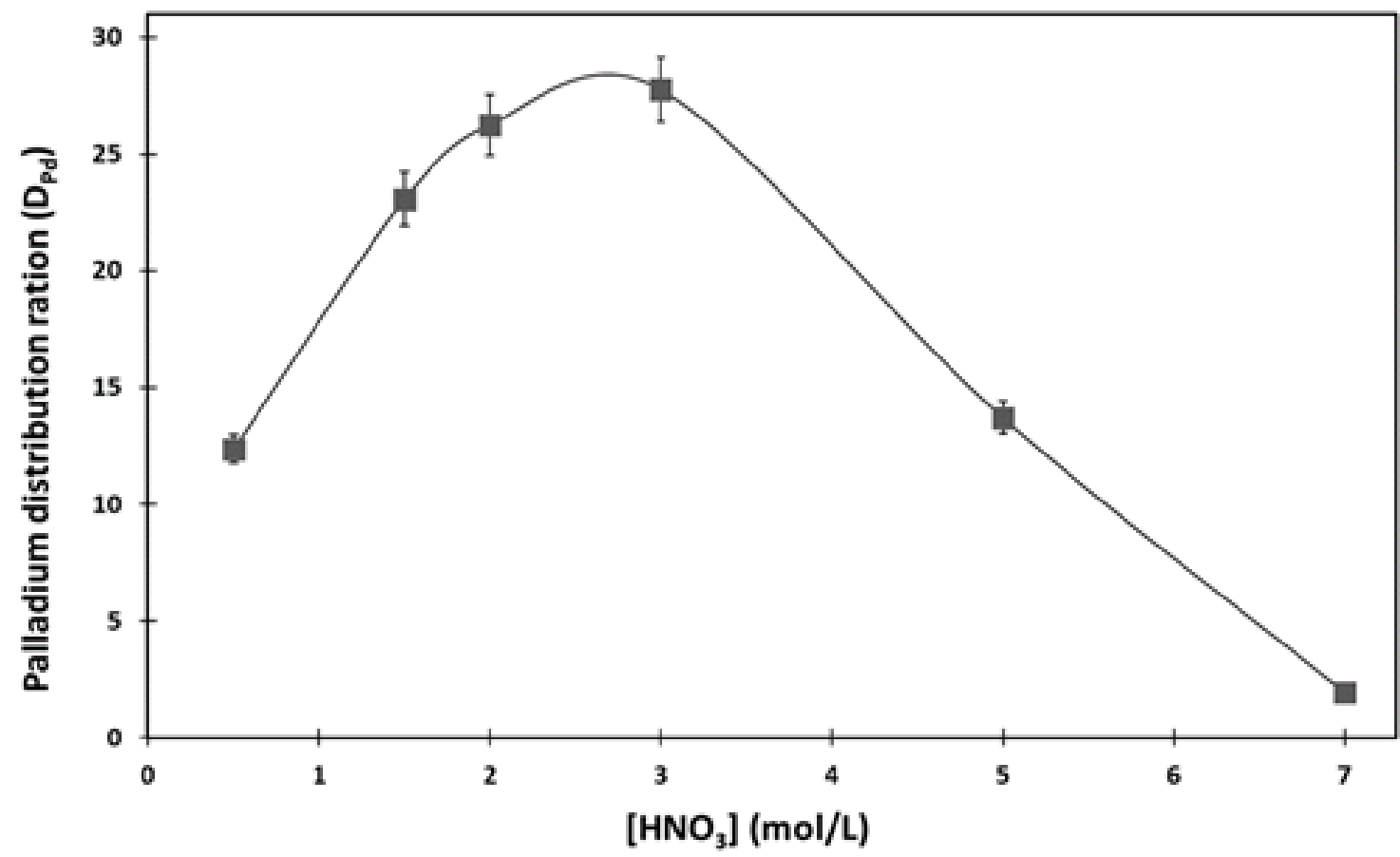

2 Figure S10: $\mathrm{Pd}(\mathrm{II})$ distribution ratio with 0.2M THMA in toluene with added 3 DHA at equilibrium (24 h extraction duration). DHA molar percentage $0 \mathrm{~mol} \%$ 4 to $50 \mathrm{~mol} \%$ respective to THMA, initial $[\mathrm{Pd}]_{\mathrm{aq}} 500 \mathrm{mg} / \mathrm{L},\left[\mathrm{HNO}_{3}\right]_{\mathrm{aq}} 5 \mathrm{M}, \mathrm{A} / \mathrm{O}=1$.

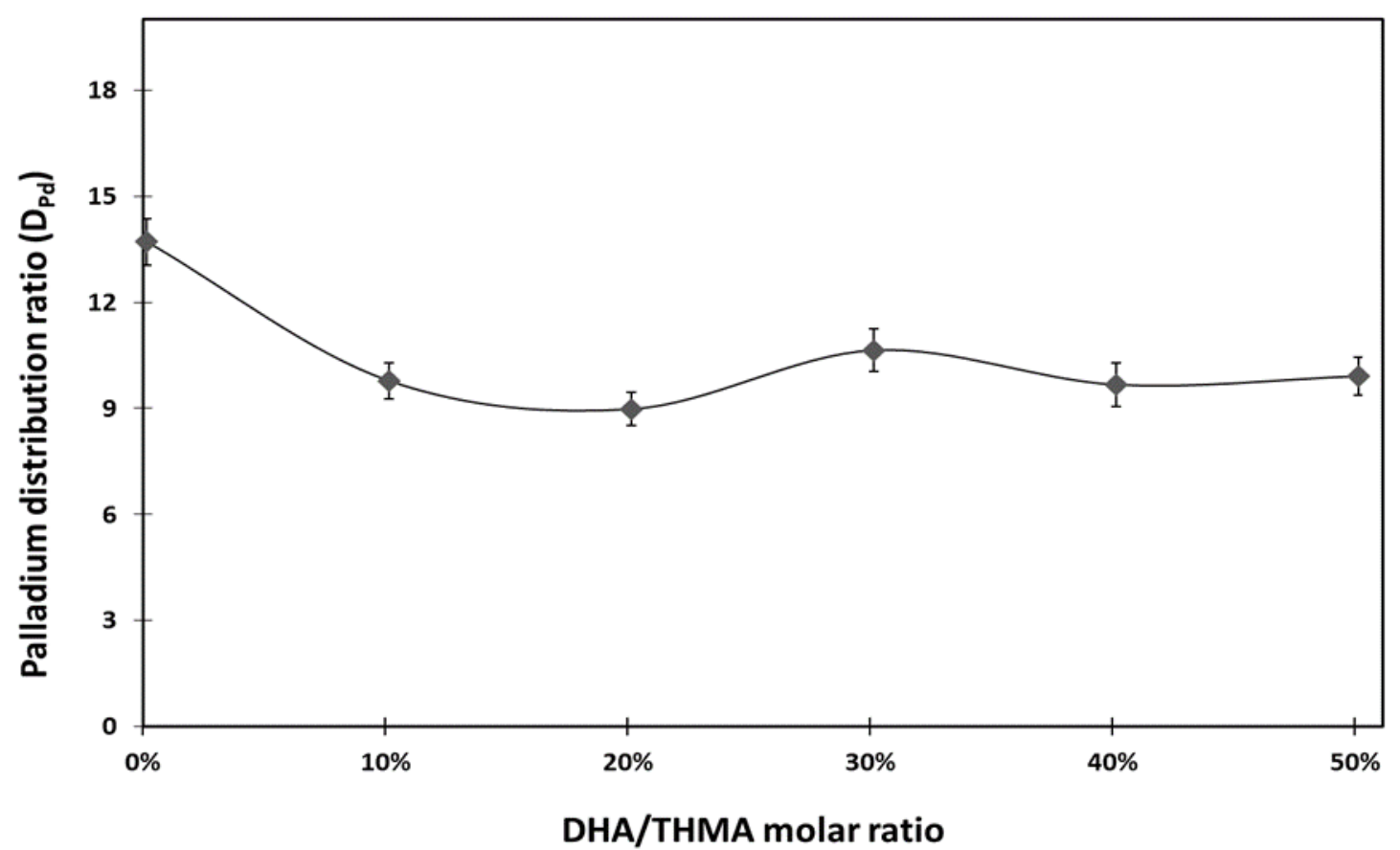


2

3 
1 Figure S11: ${ }^{1} \mathrm{H}$ NMR spectra (400 MHz, $100 \mathrm{MHz}$, solvent $\mathrm{CDCl}_{3}$ ) of (a) crude 2 THMA and (b) Dihexylamine (DHA).

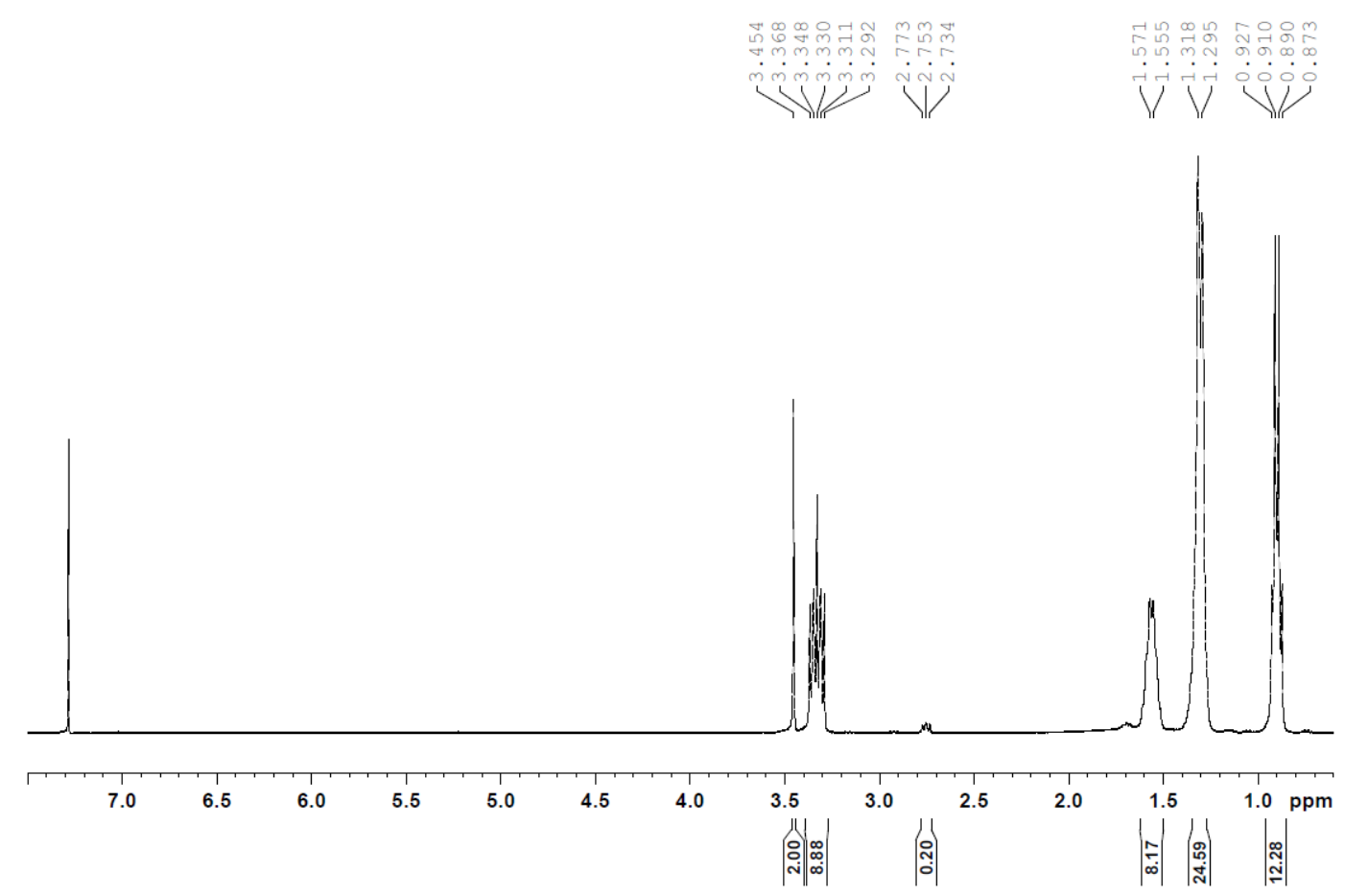

3 (a)

4 
1 (b)

2

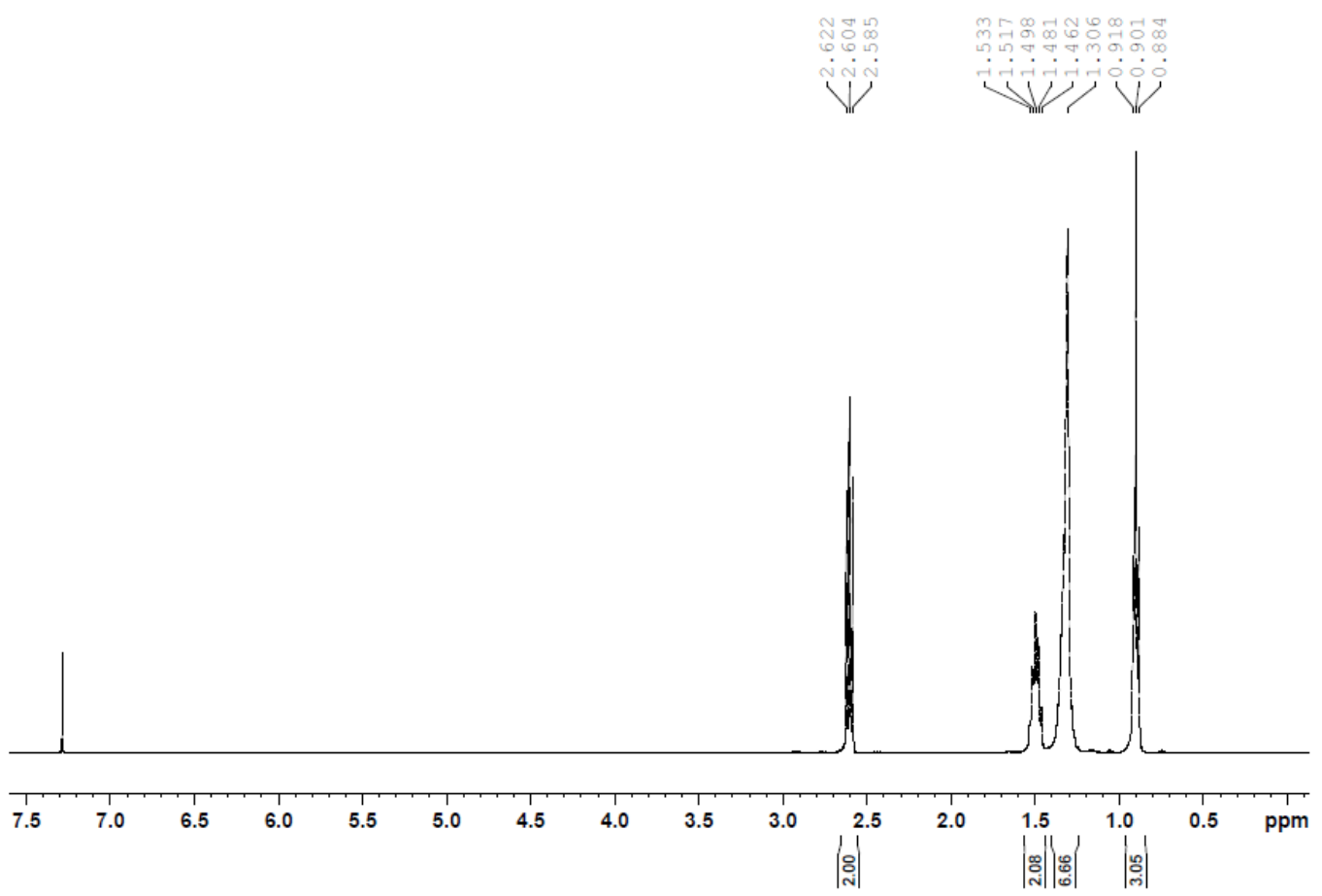

